Article

\title{
Cyclic AMP Regulates Key Features of Macrophages via PKA: Recruitment, Reprogramming and Efferocytosis
}

\author{
Graziele L. Negreiros-Lima ${ }^{1,+}{ }^{\circledR}$, Kátia M. Lima ${ }^{2,+}{ }^{(0)}$, Isabella Z. Moreira ${ }^{1}(\mathbb{D}$, \\ Bruna Lorrayne O. Jardim ${ }^{1}$, Juliana P. Vago ${ }^{3}{ }^{\circ}$, Izabela Galvão ${ }^{4}$, Lívia Cristina R. Teixeira ${ }^{1}{ }^{(\mathbb{B}}$, \\ Vanessa Pinho $^{4}\left(\mathbb{D}\right.$, Mauro M. Teixeira ${ }^{3}$, Michelle A. Sugimoto ${ }^{5}$ and Lirlândia P. Sousa and $^{1,2 * \mathbb{D}}$ \\ 1 Departamento de Análises Clínicas e Toxicológicas, Faculdade de Farmácia, Universidade Federal de Minas \\ Gerais, Belo Horizonte 31270-901, Brazil; grazieleleticia17@gmail.com (G.L.N.-L.); \\ bella_zm@hotmail.com (I.Z.M.); gardenbru@hotmail.com (B.L.O.J.); liviacrteixeira@gmail.com (L.C.R.T.) \\ 2 Programa de Pós-Graduação em Ciências Farmacêuticas, Faculdade de Farmácia, Universidade Federal de \\ Minas Gerais, Belo Horizonte 31270-901, Brazil; katiamaciellima@yahoo.com.br \\ 3 Departamento de Bioquímica e Imunologia, Instituto de Ciências Biológicas, Universidade Federal de Minas \\ Gerais, Belo Horizonte 31270-901, Brazil; julypri@gmail.com (J.P.V.); mmtex.ufmg@gmail.com (M.M.T.) \\ 4 Departamento de Morfologia, Instituto de Ciências Biológicas, Universidade Federal de Minas Gerais, \\ Belo Horizonte 31270-901, Brazil; izabelag@gmail.com (I.G.); vpinhos@gmail.com (V.P.) \\ 5 Programa de Pós-Graduação em Doenças Infecciosas e Medicina Tropical, Escola de Medicina, \\ Universidade Federal de Minas Gerais, Belo Horizonte 30130-100, Brazil; michellesugimoto@gmail.com \\ * Correspondence: lipsousa72@gmail.com; Tel.: +55-31-3409-6883 \\ + These authors contributed equally to this work.
}

Received: 31 October 2019; Accepted: 1 January 2020; Published: 6 January 2020

\begin{abstract}
Macrophages are central to inflammation resolution, an active process aimed at restoring tissue homeostasis following an inflammatory response. Here, the effects of db-cAMP on macrophage phenotype and function were investigated. Injection of db-cAMP into the pleural cavity of mice induced monocytes recruitment in a manner dependent on PKA and CCR2/CCL2 pathways. Furthermore, db-cAMP promoted reprogramming of bone-marrow-derived macrophages to a M2 phenotype as seen by increased Arg-1/CD206/Ym-1 expression and IL-10 levels (M2 markers). Db-cAMP also showed a synergistic effect with IL-4 in inducing STAT-3 phosphorylation and Arg-1 expression. Importantly, db-cAMP prevented IFN- $\gamma /$ LPS-induced macrophage polarization to M1-like as shown by increased Arg- 1 associated to lower levels of M1 cytokines (TNF- $\alpha / \mathrm{IL}-6$ ) and p-STAT1. In vivo, db-cAMP reduced the number of M1 macrophages induced by LPS injection without changes in M2 and Mres numbers. Moreover, db-cAMP enhanced efferocytosis of apoptotic neutrophils in a PKA-dependent manner and increased the expression of Annexin A1 and CD36, two molecules associated with efferocytosis. Finally, inhibition of endogenous PKA during LPS-induced pleurisy impaired the physiological resolution of inflammation. Taken together, the results suggest that cAMP is involved in the major functions of macrophages, such as nonphlogistic recruitment, reprogramming and efferocytosis, all key processes for inflammation resolution.
\end{abstract}

Keywords: inflammation resolution; db-cAMP; macrophage recruitment; macrophage reprogramming; efferocytosis

\section{Introduction}

Inflammation is a complex host response against invading pathogens or following sterile tissue injury. The inflammatory response is a spatially and temporally orchestrated process, in which cells 
and mediators collaborate to neutralize and eliminate the damaging stimuli to allow maintenance of homeostasis. Inflammation can be divided into three main phases: onset, resolution and the more recently described post-resolution phase [1-4]. If successful, the inflammatory response tends to progress from the onset to the post-resolution phase through a coordinated series of molecular and cellular events that lead to the restoration of tissue structure, organ function, and 'adapted homeostasis' [5]. A failed or impaired resolution may underpin the pathogenesis of various chronic inflammatory or autoimmune diseases, such as rheumatoid arthritis, asthma and multiple sclerosis $[3,4,6]$. Ideally, the inflammatory response protects the host, is self-limiting and progresses to complete resolution [7].

The resolution of inflammation is an active process involving biochemical mediators and signaling pathways controlling switching from pro-inflammatory mediators generation to production of pro-resolving molecules, leukocyte apoptosis (especially of neutrophils) followed by efferocytosis, and switching from pro-inflammatory to pro-resolving cell phenotypes (especially relevant to macrophages) [6,7]. Clearance of apoptotic cells by efferocytosis is an important event that brings about resolution of inflammation and induces remarkable macrophage phenotypic and functional changes [8]. Several studies have shown the ability of macrophages to adopt different phenotypes during an inflammatory process [9]. In brief, M1 macrophages (classically activated macrophages) are involved in the beginning of inflammation and enable host defense against infection, whereas M2 (alternatively activated macrophages) and proresolving (Mres) macrophages have anti-inflammatory and tissue remodeling properties, playing key roles on resolution of inflammation [10-12]. The unique ability of macrophages to respond to different types of agonists and to exhibit distinct functions is accompanied by changes in thousands of different genes, transcription factors, cell surface markers and cytokines [13]. This process is referred to as macrophage reprogramming or repolarization [14,15]. Responding to different microenvironments, primary macrophages (M0) can be polarized toward pro-inflammatory (M1) or anti-inflammatory (M2) phenotypes [16]. M1-like macrophages can be re-educated to $\mathrm{M} 2$ and consequently to the Mres phenotypes by various effector molecules or following the uptake of apoptotic cells [10,17-20]. Conversion from M2 to M1 has also been reported, a feature especially relevant to cancer research [21,22]. Macrophage polarization and reprogramming play important roles in the maintenance of immune system homeostasis [23] and provide targets for treating diseases characterized by abnormalities in macrophage function and activation status [24,25], such as cancer and atherosclerosis.

cAMP is a second intracellular messenger produced by adenylate cyclase (AC) from ATP, and its levels are regulated by phosphodiesterases (PDEs) [26,27]. cAMP has been identified as an important intracellular mediator impacting the performance of macrophage functions such as phagocytosis [28] and reprogramming [29-31]. Evidence also suggest that elevation of cAMP is an important intracellular event for inflammation resolution [29,32-34]. Studies have shown that pro-resolving mediators such as resolvin (Rv) D2 [35], RvD1 [36], melanocortin peptides [37,38] and Annexin A1 (AnxA1) [39] can have their activities mediated by cAMP activation. We have previously shown that cAMP elevating agents up-regulate AnxA1 in vivo and in cultured macrophages, and that AnxA1, in turn, is involved in the pro-resolving actions of such compounds [32]. Since AnxA1 is a molecule endowed with several pro-resolving properties $[3,39,40]$, cAMP seems to be a link between different pathways, widening the resolution cascade [3,32]. Noteworthy, the use of selective phosphodiesterase 4 (PDE4) inhibitors (which promote increased intracellular cAMP levels) for the treatment of predominantly inflammatory diseases, such as Alzheimer, psoriasis, arthritis, chronic obstructive pulmonary disease (COPD), and asthma has been widely studied [41-43], and roflumilast, an active oral PDE4 inhibitor, was approved by the FDA aiming to reduce COPD exacerbations [43]. Although the importance of cAMP in the resolution of inflammation is evident, the mechanisms by which cAMP acts in the resolution process are still not completely elucidated.

In the present study, we have investigated the effect of db-cAMP, a cAMP mimetic, on key functions of macrophages in the context of inflammation resolution. Our data suggest that db-cAMP 
mediates monocyte recruitment in a CCR2/CCL2- and PKA-dependent manner. Furthermore, db-cAMP favors an M2-like macrophage phenotype, either alone or in the presence of IFN- $\gamma /$ LPS stimuli and amplifies the IL-4-induced M2 phenotype. It also increases the frequency of macrophages expressing engulfment molecules and the efferocytosis of apoptotic neutrophils both in vitro and in vivo. Finally, inhibition of the cAMP effector protein PKA, in the course of acute pleurisy induced by LPS impairs self-resolving inflammation. Our results support that cAMP is involved in the major functions of macrophages such as nonphlogistic recruitment, reprogramming and efferocytosis, all key processes for inflammation resolution.

\section{Materials and Methods}

\subsection{Animals}

All described procedures had prior approval from the Animal Ethics Committee of Universidade Federal de Minas Gerais (CEUA/UFMG, protocol number 183/2017) and Research Ethics Committee of Universidade Federal de Minas Gerais (COEP/UFMG, protocol number 0319020300-11). Male BALB/c mice (8-10 weeks) obtained from the Center of Bioterism of Universidade Federal de Minas Gerais (Belo Horizonte, Brazil) had free access to food and water (ad libitum) and were housed under standard conditions of humidity (50-60\%), light (12 h/12 h light/dark cycle) and temperature $\left(22 \pm 1^{\circ} \mathrm{C}\right)$.

\subsection{Drugs, Reagents, and Antibodies}

Db-cAMP, H89, staurosporine, CFSE and LPS (from Escherichia coli serotype O:111:B4) were from Sigma-Aldrich (San Luis, MO, USA); IFN- $\gamma$ and IL-4 were from Biolegend (San Diego, CA, USA); RS504393 (Tocris, Bristol, England, UK); western blot antibodies were from Sigma ( $\beta$-actin), Cell Signaling Technology (Danvers, MA, USA; STAT1, p-STAT1, p-STAT3, secondary anti-rabbit peroxidase conjugate antibody) or Santa Cruz Biotechnology (Dallas, TX, USA; secondary anti-mouse peroxidase conjugate antibody); ELISA kits for measurement of IL-10, TGF- $\beta$, CCL2, IL- 6 and TNF- $\alpha$ were from R\&D Systems (Minneapolis, MN, USA). The fluorescent monoclonal antibodies were anti-F4/80 (PE-Cy7 or APC, eBioscience, San Diego, CA, USA), anti-GR1 (PE, eBioscience), anti-CD11b (alexa fluor 488, Biolegend, San Diego, CA, USA and V500, Pharmingen), anti-rabbit secondary (Alexa fluor 488 Cell Signaling, Danvers, MA, USA), anti-AnxA1 (Santa Cruz Biotechnology), anti-Ly6C (PeCy7, Biolegend), anti-Ly6G (APCCy7 or BV421, Biolegend), anti-CD36 (APC, BD biosciences) and anti-CD3 (FITC, Pharmingen).

\subsection{Leukocyte Migration to the Pleural Cavity Induced by db-cAMP}

Mice were injected intrapleurally (i.pl.) with db-cAMP (4 mg/kg) or PBS. Cells in the pleural cavity were harvested 4, 24 and $48 \mathrm{~h}$ after db-cAMP injection by washing the cavity with $2 \mathrm{~mL}$ of PBS. In another protocol, mice were pre-treated with specific inhibitors H89 (4 mg/kg, i.pl.) or RS504393 ( $2 \mathrm{mg} / \mathrm{kg}$, i.pl.) 1h before db-cAMP injection. Cells in the pleural cavity were harvested $48 \mathrm{~h}$ after $\mathrm{db}$-cAMP injection by washing the cavity with $2 \mathrm{~mL}$ PBS. Total cell counts were determined using Turk's stain in a modified Neubauer chamber. Differential cell counting was performed using standard morphological criteria to identify cell types on cyto-centrifuge preparations (Shandon Elliott) stained with May-Grünwald-Giemsa. The results are presented as the number of cells per cavity. For a deep investigation of the leukocyte population recruited after db-cAMP, pleural cells were recovered $48 \mathrm{~h}$ after db-cAMP or PBS injection and analyzed by flow cytometry using labeling for different leukocyte populations: macrophages $\left(\mathrm{F} 4 / 80^{+}\right)$, monocytes $\left(\mathrm{Ly}_{6 \mathrm{C}}{ }^{+} \mathrm{F} 4 / 80^{-}\right)$, neutrophils $\left(\mathrm{Ly}_{6 \mathrm{G}^{+}}\right)$and lymphocytes $\left(\mathrm{CD}^{+}\right)$. The results are presented as the mean percentage of cells per cavity.

\subsection{LPS-Induced Pleurisy Model and Treatment with db-cAMP or Inihibition of PKA Using H89}

Animals received an i.pl. injection of LPS (250 ng/cavity) or PBS as previously described [32,44] and $8 \mathrm{~h}$ later (at the peak of inflammation) were treated with db-cAMP ( $4 \mathrm{mg} / \mathrm{Kg}$, i.pl.). Cells recruited 
to the pleural cavity were recovered $30 \mathrm{~h}$ following LPS challenge or PBS injection by washing the cavity with $2 \mathrm{~mL}$ of PBS. Total cell counts were determined using Turk's stain in a modified Neubauer chamber. The number of macrophages was assessed by flow cytometry using antibodies to identify three macrophages subpopulations: M1 (F4/80 low $\left.\mathrm{Gr} 1^{+} \mathrm{Cd} 11 \mathrm{~b}^{\text {med }}\right)$, M2 (F4/80 $0^{\text {high }} \mathrm{Gr} 1^{-} \mathrm{Cd} 11 \mathrm{~b}^{\text {high }}$ ) and Mres (F4/80 $\left.{ }^{\text {med }} \mathrm{Cd} 11 \mathrm{~b}^{\text {low }}\right)$, as previously described [12,44-46]. In addition, the frequency of macrophages positive for AnxA1 and CD36, important molecules for efferocytosis, was verified by flow cytometry (FACS Canto II, BD biosciences). These results are presented as the mean number or frequency of cells per cavity.

In another protocol, mice were challenged with LPS (250 ng/cavity) or PBS and further injected with H89 (4 mg/kg, i.pl.) at the peak of inflammation [44]. Cells recruited to the pleural cavity were recovered $24 \mathrm{~h}$ following LPS challenge or PBS injection by washing the cavity with $2 \mathrm{~mL}$ of PBS. To verify the effect of cAMP inhibition on the spontaneous resolution of LPS-induced pleurisy and to calculate the resolution indices [32,44,47], LPS-challenge mice were injected with H89 (4 mg/kg, i.pl) at $8 \mathrm{~h}$ and $24 \mathrm{~h}$ (booster dose) after LPS. Cells recruited to the pleural cavity were recovered at $48 \mathrm{~h}$ following LPS challenge or PBS injection by washing the cavity with $2 \mathrm{~mL}$ of PBS. Total cell counts were determined using Turk's stain in a modified Neubauer chamber. Differential cell counting was performed using standard morphological criteria to identify cell types on cyto-centrifuge preparations (Shandon Elliott) stained with May-Grünwald-Giemsa. The results are presented as the number of cells per cavity. Resolution indices were calculated as described [32,48] as: (i) magnitude ( $\Psi_{\max }$-the maximum PMN numbers in the exudates) and $\mathrm{T}_{\max }$ (time point when PMN numbers reach maximum); (ii) duration ( $\mathrm{T}_{50}$-time point when PMN numbers reduce to $50 \%$ of maximum); and (iii) resolution interval $\mathrm{R}_{i}$ (the time period when $50 \%$ PMNs are lost from the pleural cavity; i.e., $\mathrm{T}_{50}-\mathrm{T}_{\max }$ ).

\subsection{In Vivo Efferocytosis Assay}

This protocol is an adaptation of previously described protocols $[37,49]$ and it has been applied in previous publication of our group $[45,46,50]$. Mice received an intraperitoneal (i.p.) injection of zymosan $0.1 \mathrm{mg} /$ cavity. After $62 \mathrm{~h}$, the animals were treated with db-cAMP ( $4 \mathrm{mg} / \mathrm{kg}$, i.p.) for $7 \mathrm{~h}$ and after received an intraperitoneal injection (i.p.) of $10^{6}$ apoptotic human neutrophils labeled with carboxyfluorescein diacetate succinimidyl ester (CFSE). Neutrophils were isolated from peripheral blood of healthy human donors, using Histopaque 11,191 and 10,771 (Sigma-Aldrich) as previously described [48]. Isolated neutrophils were stimulated with staurosporine $(10 \mu \mathrm{M}, 1 \mathrm{~h})$ for induction of apoptosis and labeled with $10 \mu \mathrm{M}$ CFSE for $1 \mathrm{~h}$ at $37^{\circ} \mathrm{C}$ under light protection. The percentage of apoptosis was determined in cytospin preparations, counted using oil immersion microscopy $(100 \times$ objective) to determine the proportion of cells with high distinctive apoptotic morphology $[32,34,48,51]$ and $>90 \%$ were apoptotic. One hour after injection of the apoptotic neutrophils, cells from the peritoneal cavity were collected with $4 \mathrm{~mL}$ of PBS, labeled with fluorescent anti-F4/80 and analyzed by flow cytometry (FACS Canto II, BD Biosciences). Moreover, cell counts were performed on cyto-centrifuge preparations (Shandon III) stained with May-Grunwald-Giemsa to determine the percentage of cells with efferocytic morphology (macrophage with apoptotic bodies observed in their cytoplasm) $[45,46]$. The results of flow cytometry are presented as percentage of $\mathrm{F} 4 / 80^{+} / \mathrm{CFSE}^{+}$cells and mean florescence intensity (MFI) of CFSE (flow cytometer laser set at 488) or by morphological analysis by determining the proportion of macrophages that ingested apoptotic neutrophils (500 cells/slides were counted).

\subsection{Isolation and Culture of Murine Bone Marrow-Derived Macrophages (BMDMs)}

BMDMs were prepared as previously described [46,52] with modifications. Bone marrow was collected from tibias and femurs of BALB/c mice and washed with RPMI (Cultilab, Campinas, São Paulo, Brazil). The suspension obtained was then centrifuged for $5 \mathrm{~min}$ at $1200 \times \mathrm{g}$. The pellet of cells was resuspended with complete conditioned media for BMDM differentiation [RPMI with $20 \%(v / v)$ heat-inactivated fetal bovine serum (FBS) and 30\% (v/v) L929 cell-conditioned medium (LCCM)], seeded on tissue culture plates, and incubated at $37{ }^{\circ} \mathrm{C}$ with $5 \% \mathrm{CO}_{2}$. After 3 days, the medium 
was supplemented with additional complete conditioned media. At day 7 the supernatant was removed, and adherent macrophages were detached using a cell scraper and plated for the different experiments, as described below. Cell differentiation and purity was determined by flow cytometry using the anti-F4/80, marker for macrophages. To induce macrophage polarization to M1-like or M2-like phenotypes, BMDMs were treated with different mouse recombinant proteins as follow: IFN- $\gamma$ $(10 \mathrm{ng} / \mathrm{mL})+$ LPS $(10 \mathrm{ng} / \mathrm{mL})$ to induce M1 macrophages or IL-4 (20 ng/mL) to induce M2 macrophages.

\subsection{RAW264.7 Cell Culture}

RAW264.7 murine macrophages were obtained from the American Type Culture Collection (ATCC, Manassas, VA, USA). The cell cultures were maintained in DMEM (Cultilab) supplemented with $10 \%$ $(v / v) \mathrm{FBS}$ at $37^{\circ} \mathrm{C}$ in $5 \% \mathrm{CO}_{2}$. After reaching 70-80\% confluence, cells were serum-deprived overnight, and cell viability was determined using a trypan blue dye exclusion assay. To induce macrophage polarization, RAW264.7 cells were treated with different mouse recombinant proteins as follow: IFN- $\gamma$ $(10 \mathrm{ng} / \mathrm{mL})+\mathrm{LPS}(10 \mathrm{ng} / \mathrm{mL})$ to induce M1 macrophages or IL-4 (20 ng/mL) to induce M2 macrophages.

\subsection{In Vitro Efferocytosis Assay}

In vitro efferocytosis assay was performed as previously described [46], by co-culturing BMDMs with human apoptotic neutrophils labeled with CFSE in a proportion of three apoptotic neutrophils: one macrophage for $1 \mathrm{~h}$. Neutrophils that had not been phagocytosed were removed by vigorous washing of the wells with PBS three times. Efferocytosis by adherent macrophages was assessed by flow cytometry (FACS Canto II, BD biosciences), and the results were expressed as mean florescence intensity (MFI) of CFSE in the F4/80+ macrophages (flow cytometer laser set at 488).

\subsection{Western Blotting}

Whole-cell extracts were prepared as described [32,44]. The protein content of the lysate was determined by Bradford assay reagent (Bio-Rad, Hercules, CA, USA). Cell lysates (40 $\mu$ g) were electrophoresed on denaturing 8-10\% polyacrylamide SDS gels under reducing conditions and electrotransferred to nitrocellulose membranes. Membranes were blocked for $1 \mathrm{~h}$ with PBS containing $5 \%(w / v)$ nonfat dry milk and PBS containing 0.1\% Tween-20 (Synth), washed three times and then incubated overnight with specific primary antibodies for STAT1(1:1000), p-STAT3 (1:1000), p-STAT1 (1:1000) or $\beta$-actin (1:10000) in PBS containing 5\% (w/v) BSA and 0.1\% Tween-20. After washing, the membranes were incubated with appropriate horseradish peroxidase-conjugated antibody (1:3000). Immunoreactive bands were Chicago, IL, USA). For densitometry analysis, membranes were scanned, and the bands were quantified using ImageJ software (ImageJ, National Institutes of Health, Bethesda, MD, USA). The results were expressed as arbitrary units and normalized to the values of $\beta$-actin or STAT1 in the same sample.

\subsection{0. qPCR Analysis of M1 and M2 Macrophage Markers}

Total RNA from BMDMs was extracted using the TRIzol ${ }^{\text {TM }}$ Reagent (Invitrogen, Carlsbad, CA, USA) according to the manufacturer's instructions. The cDNA was synthesized using $1 \mu \mathrm{g}$ of RNA with the SuperScript III Reverse Transcriptase (Invitrogen), according to the manufacturer's instructions. Real-time PCR was performed in duplicate, with obtained cDNA, specific primers and Power SYBR Green PCR Master Mix (Applied Biosystems, Foster City, CA, USA), using the StepOne ${ }^{\mathrm{TM}}$ System (Applied Biosystems). The data were analyzed using StepOne ${ }^{\mathrm{TM}}$ System software with a cycle threshold $(\mathrm{Ct})$ in the linear range of amplification and then processed by the $2^{-\triangle \Delta C t}$ method. The dissociation step was always included to confirm the absence of unspecific products. GAPDH was used as an endogenous control to normalize the variability in expression levels and results were expressed as fold increase. Expression levels for Arginase-1, mannose-receptor (CD206) and iNOS were calculated. Primers (IDT) used were as follows: iNOS (5'-AGCACTTTGGGTGACCACCAGGA-3; 5' -AGCTAAGTATTAGAGCGGCGGCA-3’), Arginase-1 
(5'-TGACATCAACACTCCCCTGACAAC-3'; 5'-GCCTTTTCTTCCTTCCCAGCAG-3'), Mannosereceptor-CD206 (5'-CATGAGGCTTCTCCTGCTTCTG-3; 5'-TTGCCGTCTGAACTGAGATGG-3), GAPDH (5'-ACGGCCGCATCTTCTTGTGCA-3'; 5' -CGGCCAAATCCGTTCACACCGA-3').

\subsection{ELISA Assay}

The levels of the chemokines CXCL1 and CCL2, and cytokines TNF- $\alpha$, IL-6, IL-10 and TGF- $\beta$ were measured in the supernatants obtained from cell cultures or pleural cavity washes by ELISA, using commercially available antibodies according to the procedures supplied by the manufacturer (R\&D Systems, Minneapolis, MN, USA).

\subsection{Statistical Analysis}

The data were analyzed by one-way analysis of variance (One-way ANOVA), followed by the Tukey test. When only two groups were evaluated, a Student $t$ test was used. A value of $p<0.05$ was considered significant. The results were presented as mean \pm SEM (standard error of the mean). Calculations were performed using the GraphPadPrism 7.0 software for Windows (GraphPad Software, La Jolla, CA, USA).

\section{Results}

3.1. Db-cAMP Promotes Nonphlogistic Monocyte Recruitment to the Pleural Cavity of Mice Associated with Increased CCR2 Expression and CCL2 Levels and Depend on CCR2 and PKA

To investigate the ability of cAMP to induce leukocyte recruitment in vivo, db-cAMP was injected into the pleural cavity of $\mathrm{BALB} / \mathrm{c}$ mice and the cells were collected at different time points. Db-cAMP induced a time-dependent influx of leukocytes into the pleural cavity, with increased cell numbers observed at 24 and $48 \mathrm{~h}$ time points (Figure 1A). The cells recruited to the pleural cavity were almost entirely mononuclear cells without any significant modification in neutrophil numbers. Indeed, $\mathrm{db}$-cAMP-induced cell recruitment occurred in a nonphlogistic manner with an early $(4 \mathrm{~h})$ increase of IL-10 levels that persisted for up to $48 \mathrm{~h}$, with no changes in the levels of the neutrophil chemoattractant CXCL1 and the pro-inflammatory cytokines TNF- $\alpha$ and IL-6 levels (Figure 1B).

To identify cell populations that migrated to the cavity, we analyzed the recruited cells at $48 \mathrm{~h}$ after db-cAMP injection for surface expression of F4/80, CD3, Ly6G and Ly6C. Our results show that injection of db-cAMP increases monocyte $\left(\mathrm{Ly}_{6} \mathrm{C}^{+} \mathrm{F} 4 / 80^{-}\right)$recruitment (Figure $\left.1 \mathrm{C}, \mathrm{D}\right)$, without changing the frequency of macrophages $\left(\mathrm{F} 4 / 80^{+}\right)$. Confirming the pleural counts of the cytospin slides (showed in Figure 1A), flow cytometry analysis showed that db-cAMP injection did not increase the frequency of neutrophils $\left(\mathrm{Ly}_{6 \mathrm{G}}{ }^{+}\right)$or lymphocytes $\left(\mathrm{CD}^{+}\right)$in the pleural cavity when compared with PBS-injected mice (Figure 1D). Interestingly, there was increased frequency of CCR2 ${ }^{+}$monocytes (Figure 1E) associated with an early increased levels of CCL2 at $4 \mathrm{~h}$ time point (Figure 1F), whose levels remained until $48 \mathrm{~h}$ after db-cAMP injection (PBS: $8.6 \pm 1.8$; db-cAMP: $50.0 \pm 18.1$; CCL2 levels in pg/mL, $p<0.05, n=5)$. The involvement of CCL2/CCR2 axis, an important determinant for mononuclear cell migration [53,54] in db-cAMP-induced migration was also evaluated by pharmacological inhibition of CCR2. Mice were pretreated with the antagonist of CCR2, RS504393 (2 mg/kg i.pl.), $1 \mathrm{~h}$ before $\mathrm{db}$-cAMP and we can observe that receptor inhibition decreased the db-cAMP-induced recruitment of mononuclear cells (Figure 1G). 


\begin{tabular}{cll}
\hline $\begin{array}{c}\text { Oh } \\
\text { db-cAMP }\end{array}$ & Pleural wash: & \multicolumn{1}{c}{$48 \mathrm{~h}$} \\
$(4 \mathrm{mg} / \mathrm{kg}$ i.pl.) & - Cytospin & Pleural wash: \\
& - ELISA & - Cytospin \\
& & - ELISA \\
& & - Flow cytometry
\end{tabular}

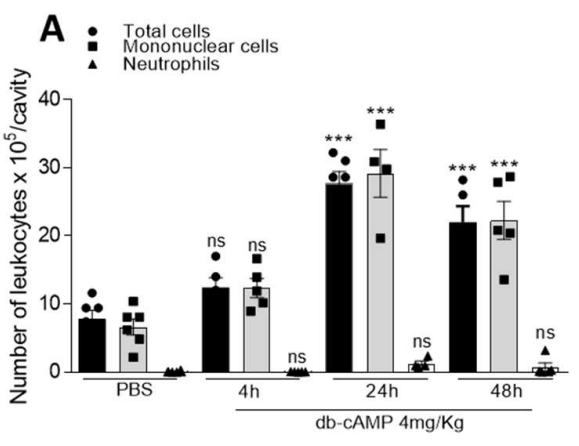

C
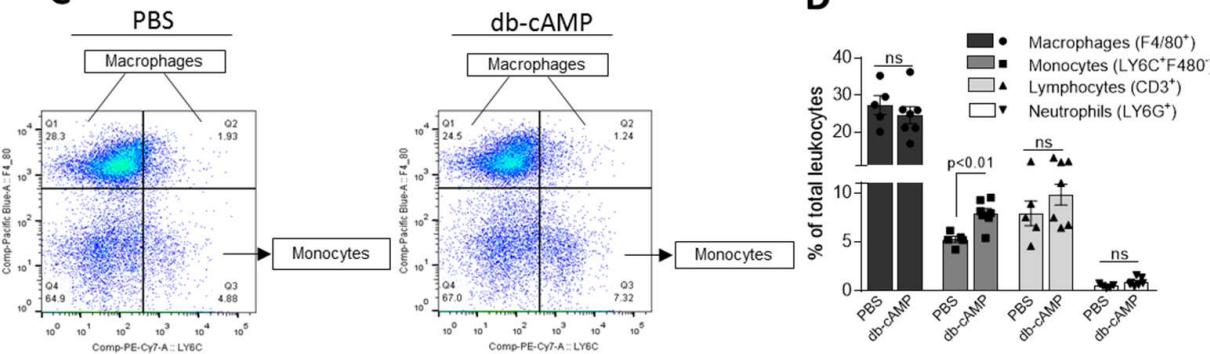

B

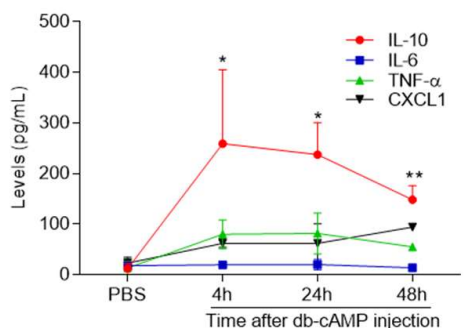

D
E

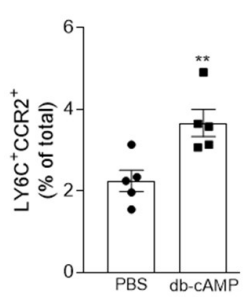

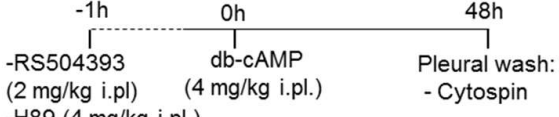
$-\mathrm{H} 89$ (4 mg/kg i.pl.)

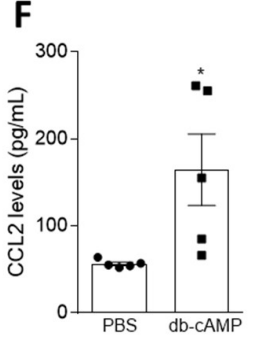

\section{G}

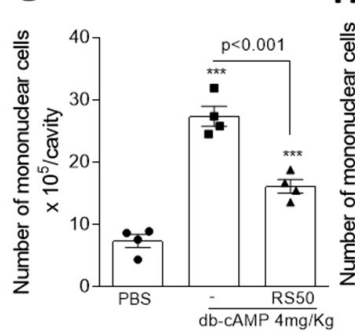

H

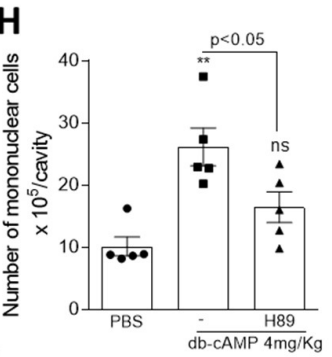

Figure 1. Time-course of leukocyte recruitment to the pleural cavity of mice after db-cAMP injection and effect of CCR2 and PKA inhibition. BALB/c mice were challenged by an i.pl. injection of db-cAMP $(4 \mathrm{mg} / \mathrm{kg})$ and the cells present in the pleural cavity were harvested at 4,24 and $48 \mathrm{~h}$. Pleural cells were processed for total and differential leukocyte counts of cytospin preparations by light microscopy (A). Levels of cytokines and chemokine (in pg/mL) (B) were measured by ELISA assay in the supernatants obtained from pleural cavity washes after PBS or db-cAMP injection. Flow cytometry analysis of pleural leukocytes collected $48 \mathrm{~h}$ after db-cAMP ( $4 \mathrm{mg} / \mathrm{kg}$ ) or PBS injection (C,D). Representative dot plots (C) and percentage of lymphocytes, macrophages, monocytes, neutrophils (from the total leukocytes) (D), and monocytes CCR2 ${ }^{+}$(E). Levels of the chemokine CCL2 (in pg/mL) were measured by ELISA assay in supernatants obtained from pleural cavity washes $4 \mathrm{~h}$ after db-cAMP injection (F). Mice were also pre-treated for $1 \mathrm{~h}$ with RS504393 (2 mg/kg, i.pl.) (G) or H89 (4 mg/kg, i.pl.) (H) and cells from pleural cavity were harvested $48 \mathrm{~h}$ after db-cAMP injection for counting of mononuclear cells. Results are expressed as the number of cells per cavity and are shown as the means \pm SEM of 4-6 mice in each group. ${ }^{*} p<0.05,{ }^{* *} p<0.01,{ }^{* *} p<0.001$ when compared with PBS-injected mice. 
In addition, we have investigated whether PKA (a cAMP effector protein) was involved in db-cAMP-induced mononuclear cells recruitment. For that, mice were pretreated with $\mathrm{H} 89$ (4 mg/kg, i.pl.), a PKA inhibitor, $1 \mathrm{~h}$ before db-cAMP and we can observe that PKA inhibition decreased the $\mathrm{db}$-cAMP-induced recruitment of mononuclear cells (Figure $1 \mathrm{H}$ ).

\subsection{Db-cAMP Induces Macrophage Polarization towards M2 Phenotype in a PKA Dependent Manner}

Next we examined the effect of db-cAMP on macrophage reprogramming, a key step for resolution of inflammation [10]. For this, bone marrow-derived macrophages (BMDMs) were treated with db-cAMP $(100 \mu \mathrm{M})$ for different times $(6,12$ and $24 \mathrm{~h})$ and important markers of macrophage phenotypes M1 or M2 were evaluated.

As shown in Figure 2, db-cAMP increased the M2 macrophage markers Arg-1 (Figure 2A), CD206 (Figure 2B) and Ym-1 protein (Figure S1) in different expression kinetics. Db-cAMP also induced low expression of the M1 marker iNOS (Figure 2C), suggesting that macrophage phenotype induced by $\mathrm{db}$-cAMP has a mixed profile. In addition, db-cAMP induced increased levels of IL-10 (Figure 2D) at $12 \mathrm{~h}$, following the Arg-1 expression peak, without modifying TGF- $\beta$ (Figure 2E) and TNF- $\alpha$ levels (Figure 2F). Noteworthy, db-cAMP showed similar effects on RAW 246.7 cells, by inducing the expression of Arg-1 (Figure S2A) and CD206 (Figure S2B), which peak at $24 \mathrm{~h}$, and augmented iNOS levels (Figure S2C).

To investigate if db-cAMP induces polarization of macrophages toward an M2 phenotype in a manner dependent of PKA, the main cAMP effector protein, BMDMs were pretreated for $1 \mathrm{~h}$ with the PKA inhibitor H89 $(20 \mu \mathrm{M})$, and stimulated with db-cAMP $(100 \mu \mathrm{M})$ for further $6 \mathrm{~h}$. Interestingly, pre-treatment with H89 inhibited Arg-1(Figure 2G) and CD206 (Figure 2H) expression, and IL-10 (Figure 2I) levels in response to db-cAMP, suggesting the participation of PKA in db-cAMP-induced macrophage polarization.

\subsection{Db-cAMP has Synergic Effect with IL-4 to Induce Phosphorylation of STAT3 and Arg-1 Expression}

To investigate the intracellular signaling pathways triggered during db-cAMP-induced M2 polarization, we initially evaluated whether db-cAMP would to induce activation of STAT3 and STAT6, two important pathways for IL-4-induced M2 polarization [55]. For this, BMDMs were treated for different times $(5,10$ and $30 \mathrm{~min})$ with db-cAMP $(100 \mu \mathrm{M})$ and phosphorylation of STATs 3 and 6 were analyzed by western blot. Figure $3 \mathrm{~A}$ shows that db-cAMP promoted STAT3 phosphorylation within $30 \mathrm{~min}$ after treatment. Under these same experimental conditions, it was not possible to detect pSTAT6 levels (data not shown). Then, we evaluated whether db-cAMP would have synergistic effect with IL-4 on STAT3 phosphorylation. For this, BMDMs were treated with IL-4 at low concentration $(5 \mathrm{ng} / \mathrm{mL})$, db-cAMP $(100 \mu \mathrm{M})$ or db-cAMP $(100 \mu \mathrm{M})+\mathrm{IL}-4(5 \mathrm{ng} / \mathrm{mL})$. Interestingly, an additive effect of db-cAMP with IL-4 was observed on STAT3 phosphorylation (Figure 3B). 

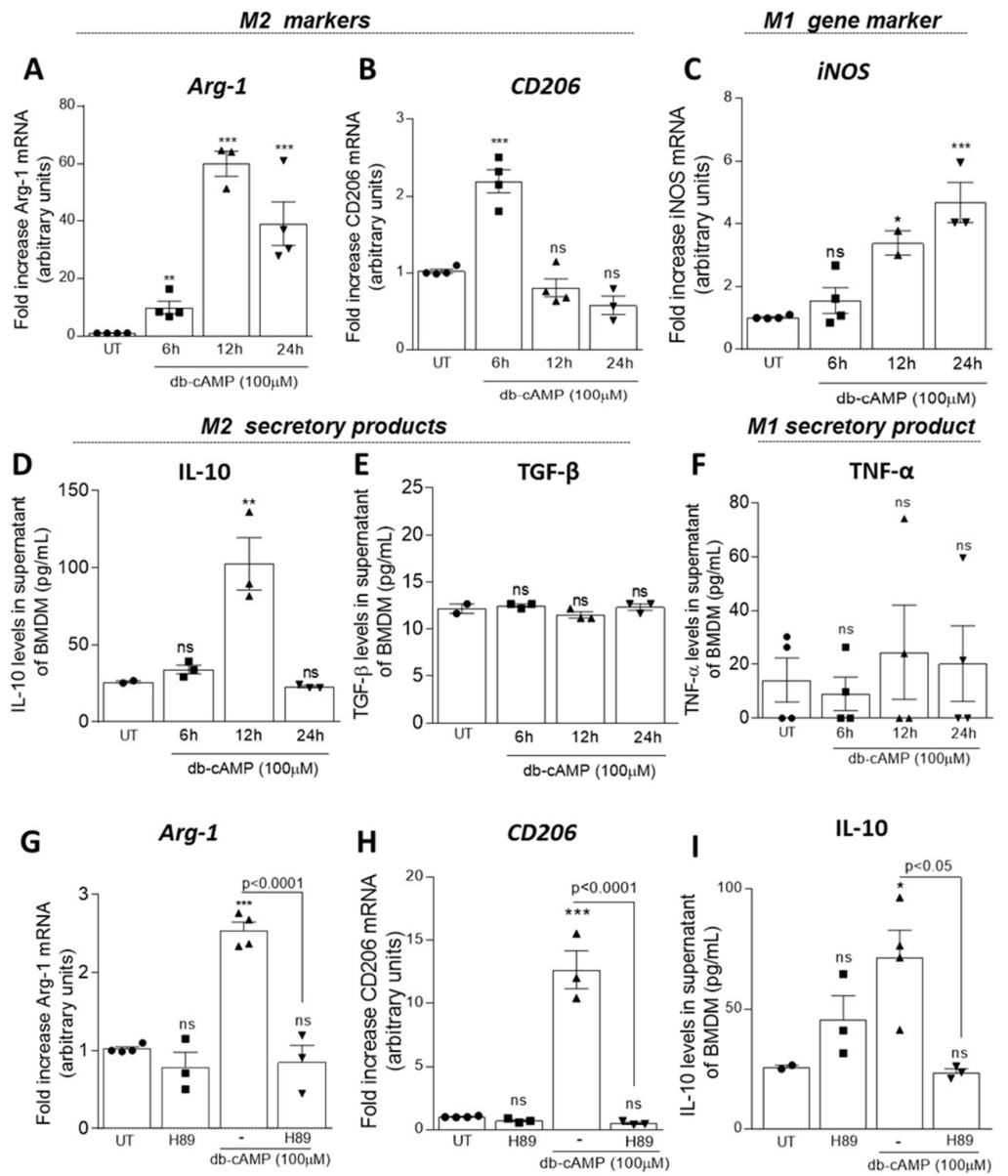

Figure 2. Effect of db-cAMP on macrophage polarization. Bone marrow from BALB/c mice was isolated and differentiated to bone-marrow-derived macrophages (BMDMs) for 7 days. Then BMDMs were treated with db-cAMP $(100 \mu \mathrm{M})$ for 6, 12 and $24 \mathrm{~h}$ and analyzed by qPCR for the expression of the M2 markers: Arginase-1 (A) and CD206 (B) and the M1 marker iNOS (C). The levels of secretory products of M2 macrophages TGF- $\beta$ and IL-10 (D,E) and M1 macrophages TNF- $\alpha(\mathbf{F})$ were measured from supernatants by ELISA assay. In (G-I) BMDMs were pretreated with H89 $(20 \mu \mathrm{M})$ for $1 \mathrm{~h}$ and then stimulated with db-cAMP $(100 \mu \mathrm{M})$ for further $6 \mathrm{~h}$ to measurement of the M2 markers Arginase-1, CD206 and IL-10. Results are expressed as fold increase (qPCR) and levels in pg/mL (ELISA), and are shown as the mean \pm SEM. ${ }^{*} p<0.05,{ }^{* *} p<0.01,{ }^{* * *} p<0.001$ when comparing with untreated (UT) BMDMs.

Next, the effect of db-cAMP plus IL-4 on the expression of the M2 marker Arg-1 was evaluated. BMDMs were either treated with db-cAMP $(100 \mu \mathrm{M})$ or IL-4 $(20 \mathrm{ng} / \mathrm{mL})$ alone or db-cAMP $(100 \mu \mathrm{M})+$ IL-4 (20 ng/mL) for $6 \mathrm{~h}$. Analysis of Arg-1 expression by qPCR also demonstrated a synergistic effect of db-cAMP with IL-4 (Figure 3C), showing increased Arg-1 expression when compared to db-cAMP or IL-4 stimuli alone. 

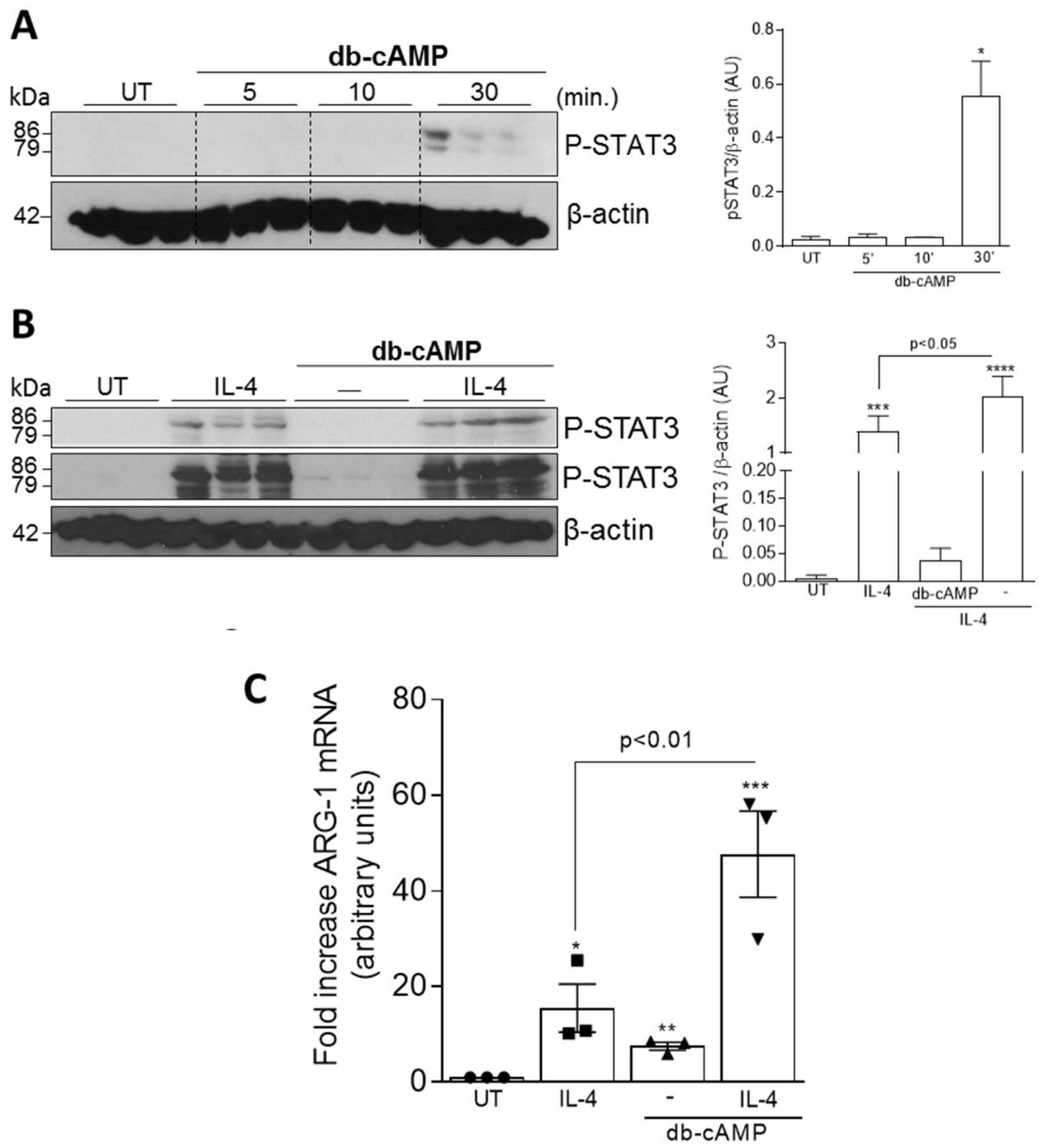

Figure 3. Effect of db-cAMP alone or in combination with IL-4 on STAT3 signaling and Arginase-1 expression. BMDMs from BALB/c mice were treated with db-cAMP $(100 \mu \mathrm{M})$ for 5, 10 and $30 \mathrm{~min}(\mathrm{~A})$ or were stimulated with IL-4 $(5 \mathrm{ng} / \mathrm{mL})$, db-cAMP $(100 \mu \mathrm{M})$ or db-cAMP $(100 \mu \mathrm{M})+\mathrm{IL}-4(5 \mathrm{ng} / \mathrm{mL})$ for $30 \mathrm{~min}$ (B). Cell lysates were subjected to western blot analysis to assess pSTAT3 (A,B). In B, two exposures of p-STAT3 are presented to show the full range of expression. $\beta$-actin was used as a loading control. Densitometry analyses are shown (A,B). In (C) BMDMs were untreated or stimulated with db-cAMP $(100 \mu \mathrm{M}), \mathrm{IL}-4(20 \mathrm{ng} / \mathrm{mL})$ or db-cAMP $(100 \mu \mathrm{M})+\mathrm{IL}-4(20 \mathrm{ng} / \mathrm{mL})$ for $6 \mathrm{~h}$, and analyzed by qPCR for the expression of Arginase-1. Results are expressed as fold increase (qPCR) and are shown as the mean \pm SEM. ${ }^{*} p<0.05,{ }^{* *} p<0.01,{ }^{* * *} p<0.001,{ }^{* * * *} p<0.0001$ when comparing with untreated (UT) BMDMs.

\subsection{Db-cAMP Re-educates M1 Macrophages toward an M2-like Phenotype Associated with Inhibition of} STAT1 Phosphorylation

Having established the effect of db-cAMP on M2 polarization, we evaluated its impact on M1 polarization induced by pro-inflammatory stimuli.

BMDMs were stimulated with db-cAMP $(100 \mu \mathrm{M})$ alone, LPS $(10 \mathrm{ng} / \mathrm{mL})+\mathrm{IFN}-\gamma(10 \mathrm{ng} / \mathrm{mL})$ or pretreated with db-cAMP $(100 \mu \mathrm{M})$ for $1 \mathrm{~h}$ and then stimulated with LPS $(10 \mathrm{ng} / \mathrm{mL})+\mathrm{IFN}-\gamma$ $(10 \mathrm{ng} / \mathrm{mL}$ ) for further $6 \mathrm{~h}$. Db-cAMP was able to induce Arg-1 expression (Figure $4 \mathrm{~A}$ ) even in the presence of the M1 stimuli (LPS + IFN- $\gamma$ ), without changing iNOS expression (Figure 4B). In addition, the pre-treatment with db-cAMP prevented the production of the pro-inflammatory cytokines TNF- $\alpha$ (Figure 4C) and IL-6 (Figure 4D), and STAT1 phosphorylation (Figure 4E), which participates in M1 signaling pathway induced by LPS + IFN- $\gamma[55]$. 

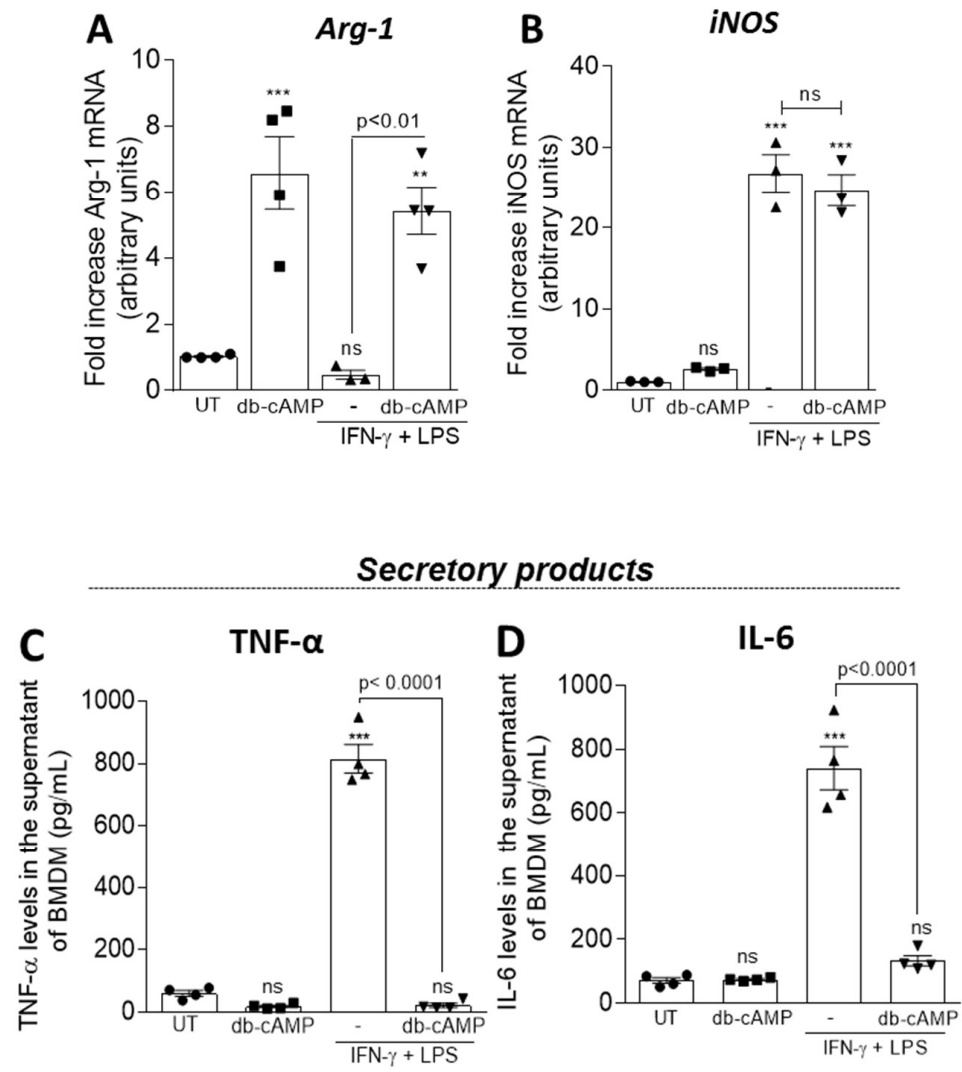

$\mathbf{E}$
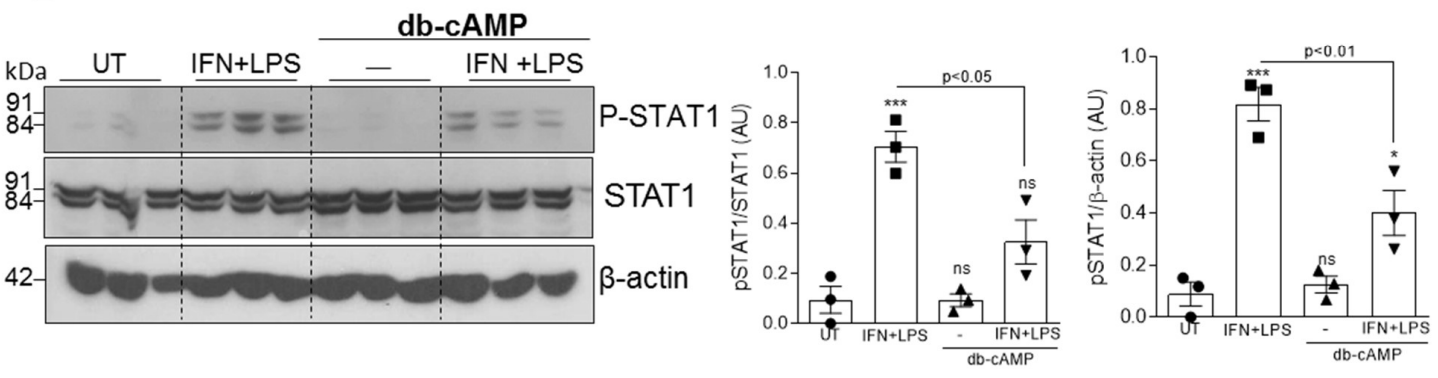

Figure 4. Effect of db-cAMP on macrophage polarization and STAT1 activation induced by IFN/LPS. BMDMs from BALB/c mice were stimulated with db-cAMP $(100 \mu \mathrm{M}), \mathrm{LPS}(10 \mathrm{ng} / \mathrm{mL})+\mathrm{IFN}-\gamma(10 \mathrm{ng} / \mathrm{mL})$ or were pretreated for $1 \mathrm{~h}$ with db-cAMP $(100 \mu \mathrm{M})$ and then stimulated with LPS $(10 \mathrm{ng} / \mathrm{mL})+\mathrm{IFN}-\gamma$ $(10 \mathrm{ng} / \mathrm{mL})$ for further $6 \mathrm{~h}$. Cells were collected for measurement of the M2 marker Arg-1 (A) and the M1 marker iNOS (B) by qPCR, and the culture supernatants were used for measurements of the secretory products of M1 - TNF- $\alpha$ (C) and IL-6 (D) by ELISA. In (E) BMDMs were stimulated with LPS (10 ng/mL) + IFN- $\gamma(10 \mathrm{ng} / \mathrm{mL}), \mathrm{db}$-cAMP $(100 \mu \mathrm{M})$, or were pretreated with db-cAMP $(100 \mu \mathrm{M})$ for $1 \mathrm{~h}$ and then stimulated LPS $(10 \mathrm{ng} / \mathrm{mL})+$ IFN- $\gamma(10 \mathrm{ng} / \mathrm{mL})$ for $30 \mathrm{~min}$. Cell lysates were subjected to western blot analysis to assess the phosphorylated (pSTAT1) and total STAT1 levels (E). qPCR, ELISA assay and WB densitometry are expressed as fold increase, levels in $\mathrm{pg} / \mathrm{mL}$ and arbitrary units, respectively, and are shown as the mean \pm SEM. ${ }^{*} p<0.05^{* *} p<0.001,{ }^{* * *} p<0.0001$ when comparing with untreated (UT) BMDMs.

3.5. Treatment of LPS-Inflamed Mice with db-cAMP Decreased the Numbers of M1 Macrophages without Modifying M2 and Mres, and Increases the Engulfment-Related Molecules AnxA1 and CD36

We next examined the role of $\mathrm{db}$-cAMP in macrophage polarization in vivo, using a well-established model of acute inflammation-a self-resolving model of pleurisy. In this model, M1-like macrophages 
are predominant in the pleural cavity within $8 \mathrm{~h}$ after LPS intrapleural injection (peak of inflammation), while M2-like macrophages predominates during the resolution-phase of inflammation (characterized by clearance of the infiltrated neutrophils) [56]. In the present work, BALB/c mice were injected with LPS (250 ng/cavity i.pl.), treated at the peak of inflammation ( $8 \mathrm{~h})$ with db-cAMP (4 mg/kg, i.pl.), and macrophages were characterized by flow cytometry $30 \mathrm{~h}$ after LPS challenge.

The evaluated time $(30 \mathrm{~h})$ was chosen because this time point precedes the resolution phase, so it is predicted still have a mixed macrophage population with M1 and M2 phenotypes into the pleural cavity.

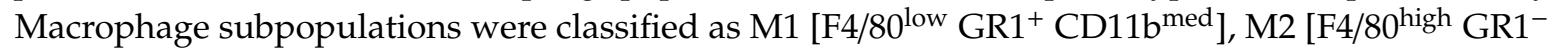
$\left.\mathrm{CD} 11 \mathrm{~b}^{\text {high }}\right]$ or Mres [F4/80 $\left.{ }^{\text {med }} \mathrm{CD} 11 \mathrm{~b}^{\text {low }}\right]$ as previously published [12,44-46]. Analysis of cells obtained from pleural lavage showed that db-cAMP decreased the number of macrophages M1 (Figure 5A), but did not change the number of M2 (Figure 5B) and Mres (Figure 5C) macrophages. Representative dot plots and histograms are shown in Figure S3. Interestingly, in this same model, db-cAMP increased the frequency of macrophages $\left(\mathrm{F} 4 / 80^{+}\right)$positive for AnxA1 (Figure 5D) and CD36 (Figure 5E), in which are molecules involved in phagocytosis of apoptotic neutrophils, a process called efferocytosis [57-65].
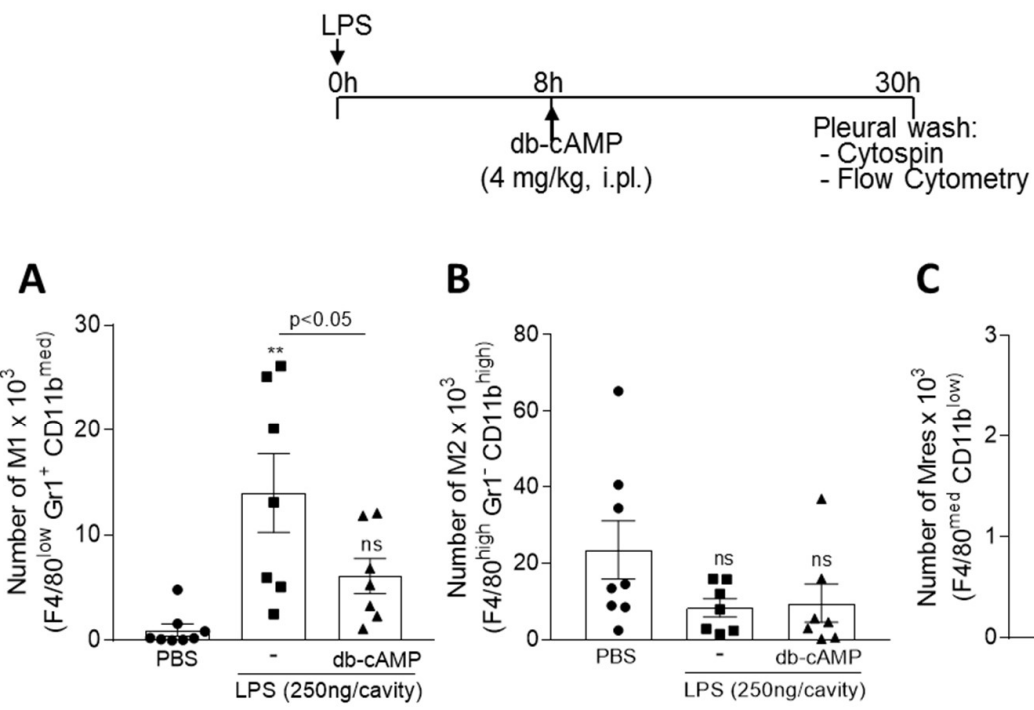

B

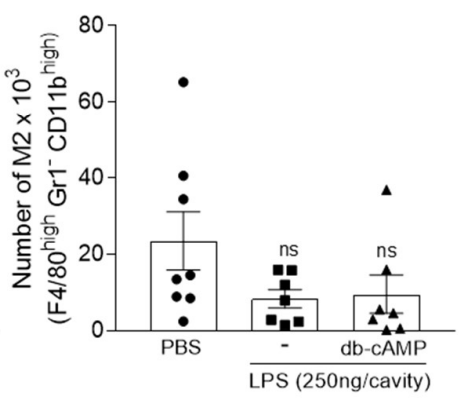

C

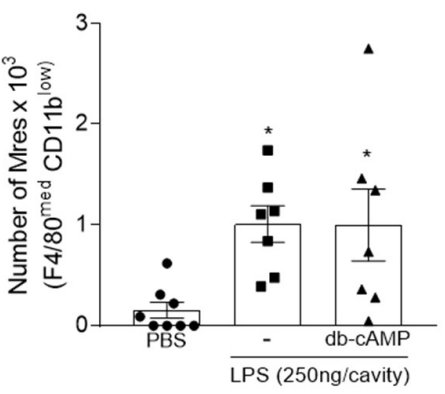

D

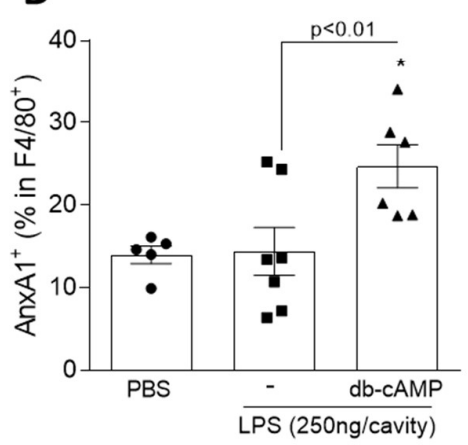

$\mathbf{E}$

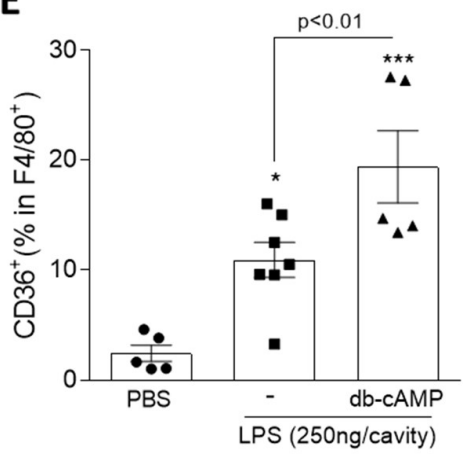

Figure 5. Effect of the treatment of LPS-inflamed mice with db-cAMP on macrophage polarization and engulfment-related molecules. BALB/c mice were injected with LPS (250 ng/cavity, i.pl.) or PBS, and $8 \mathrm{~h}$ later received an injection of db-cAMP $(4 \mathrm{mg} / \mathrm{kg}$, i.pl.). Cells present in the pleural cavity were harvested $30 \mathrm{~h}$ after LPS challenge or PBS injection. The number of M1 [F4/80 $\left.{ }^{\text {low }} \mathrm{GR} 1^{+} \mathrm{CD} 11 \mathrm{~b}^{\text {med }}\right](\mathrm{A})$, M2 [F4/80 high GR1- CD11b $\left.{ }^{\text {high }}\right]$ (B), Mres [F4/80 med CD11b low $]$ macrophages (C) and \% of AnxA1 and CD36 in F4/80 ${ }^{+}$cells (D and E) were evaluated by flow cytometry. Results are shown as the mean \pm SEM of 5-8 mice in each group. ${ }^{*} p<0.05,{ }^{* *} p<0.01,{ }^{* * *} p<0.0001$, when compared with PBS-injected mice. 


\subsection{Db-cAMP Enhances Efferocytosis of Apoptotic Neutrophils in a PKA Dependent Manner}

As db-cAMP promotes macrophage polarization to a M2-like phenotype and increases engulfment-associated molecules, all related to a pro-efferocytic macrophage phenotype [66], we next investigated whether db-cAMP plays a role in efferocytosis using previously described in vitro and in vivo efferocytosis assays [46]. Briefly, BMDMs were co-cultured with CFSE-labeled apoptotic human neutrophils (1:3, respectively) for $1 \mathrm{~h}$. Then, the cells were washed and labeled with F4/80 (macrophage marker) and analyzed by flow cytometry. Representative histograms are shown in Figure 6A. Engulfment of apoptotic neutrophils by BMDMs treated with db-cAMP were increased compared to untreated macrophages, as indicated by the higher MFI of CFSE-labeled neutrophils in $\mathrm{F} 4 / 80^{+}$cells in this group (Figure $6 \mathrm{~B}$ ). This effect was partially reduced by pretreatment of cells with $\mathrm{H} 89$ (Figure 6C). Next, we evaluated in vivo efferocytosis in a peritonitis model, as described [37,45,46,50,67]. BALB/c mice received an intraperitoneal injection of zymosan $(0.1 \mathrm{mg} / \mathrm{i} . \mathrm{p}$.) to induce macrophage recruitment. In this model of transient peritonitis, PMN cells peak at around $12 \mathrm{~h}$ (onset) followed by their clearance, and after $24 \mathrm{~h}$ there are predominance of macrophages, but still a residual of neutrophils and eosinophils [49]. After $62 \mathrm{~h}$ from zymosan injection, mice were treated with db-cAMP $(4 \mathrm{mg} / \mathrm{kg}$, i.p.) and $7 \mathrm{~h}$ later were injected intraperitoneally with CFSE-labeled apoptotic neutrophils. Cells were collected from the peritoneal exudate $1 \mathrm{~h}$ later, labeled with F4/80 and analyzed by flow cytometry and light microscopy to check for efferocytosis. Db-cAMP was able to induce increased efferocytosis, as observed by $\%$ of $\mathrm{F} 4 / 80^{+} / \mathrm{CFSE}^{+}$cells and MFI CFSE in F4/80 $0^{+}$ascertained by flow cytometry (Figure 6D-F), and morphological analysis by light microscopy (Figure 6G,H).

\subsection{Inhibition of the cAMP Pathway with a PKA Antagonist H89 Prevents Natural Resolution of Pleurisy and Decreases the Numbers of Mononuclear Cells}

We have previously shown that cAMP elevating compounds drive resolution of neutrophilic [32,34] and eosinophilic [33] inflammation by promoting apoptosis of these PMN cells.

In the present study, we gathered data showing that cAMP also has effects on other key steps of resolution: macrophage reprogramming and efferocytosis. Therefore, our next step was to evaluate the effect of endogenous cAMP in physiological resolution of inflammation. For that, we used a well-established self-resolving model of LPS-induced pleurisy, in which the intrapleural injection of LPS induces a time-dependent influx of leukocytes into the pleural cavity, characterized by early peak of neutrophil ( $8 \mathrm{~h}$ after LPS injection), and a late incoming of mononuclear cells ( $24 \mathrm{~h}$ after LPS injection) $[34,44,46,48]$. Therefore, we injected the PKA inhibitor H89 at the peak of inflammation and recovered the cells $24 \mathrm{~h}$ after, for counting of neutrophils and mononuclear cells. As can be seen, the inhibition of PKA with H89 increases the number of neutrophils (Figure 7A) and decreases the number of mononuclear cells (Figure 7B) when compared to the group of mice that did not receive the inhibitor. We also performed experiments aiming to calculate the resolution indices [47]. Mice were challenged with LPS and injected with H89 at $8 \mathrm{~h}$ and $24 \mathrm{~h}$ (booster dose). The cells were collected 8 and $48 \mathrm{~h}$ after LPS injection for evaluation of neutrophils numbers and quantification of the resolution interval $(R i)[68,69]$. Our data show that in this self-resolving model of inflammation the resolution interval ( $R i$ ) was $\sim 30 \mathrm{~h}$, whereas H89-treated animals remains with higher numbers of neutrophils into the pleural cavity and did not resolve, even at the last time point evaluated, with a predicted $R i>$ $48 \mathrm{~h}$ (Figure 7C). This data suggest that endogenous cAMP is crucial for resolves inflammation in the LPS-induced pleurisy model. 
In vitro A

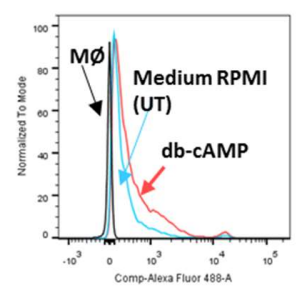

B

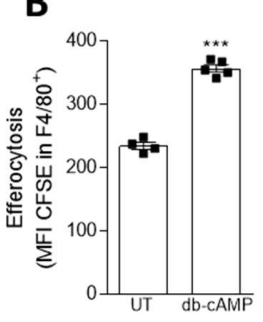

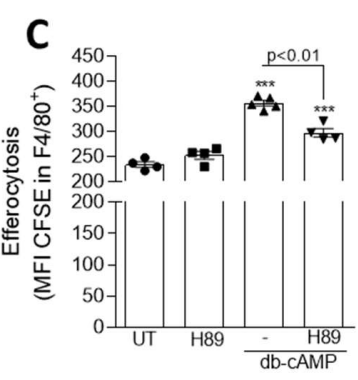

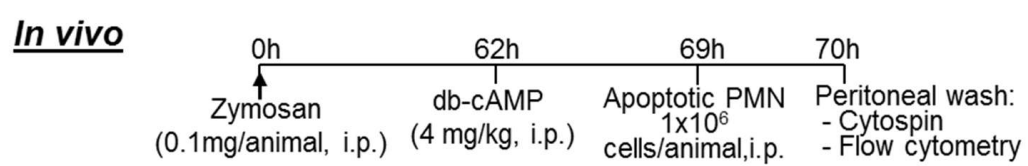

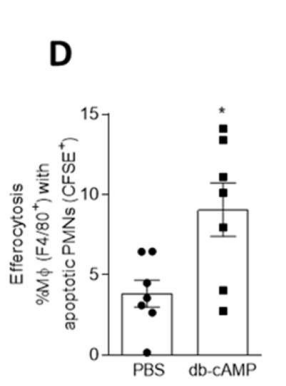

\section{$\mathbf{E}$}

PBS

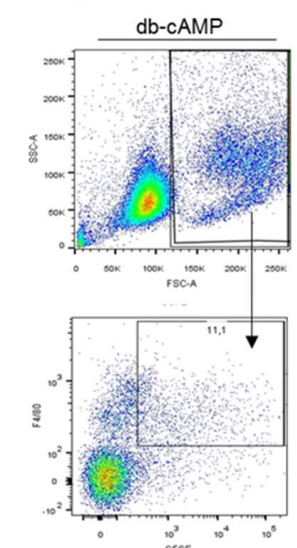

G

H
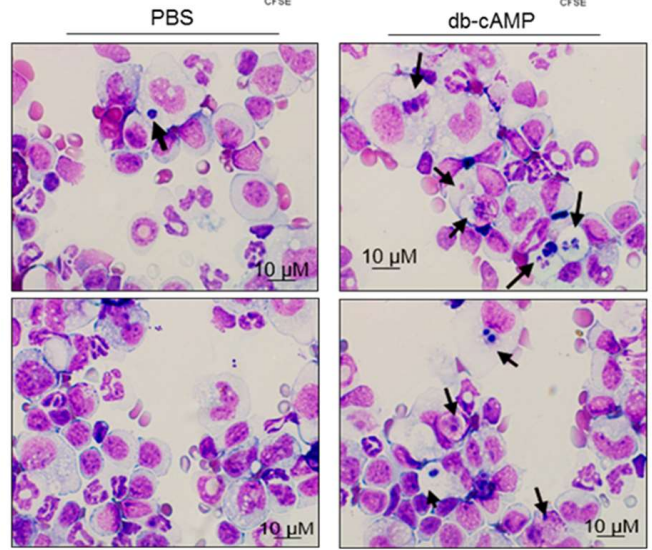

Figure 6. Effect of db-cAMP on macrophage efferocytosis. The in vitro efferocytosis assay was performed by co-culturing BMDMs from BALB/c mice with human apoptotic neutrophils labeled with CFSE in a proportion of 3 neutrophils per macrophage. Macrophages were treated with db-cAMP $(100 \mu \mathrm{M})$ for $24 \mathrm{~h}(\mathbf{B})$, or pre-treated with H89 $(20 \mu \mathrm{M})$ for $1 \mathrm{~h}$ prior to treatment with db-cAMP for further $24 \mathrm{~h}$ (C). Efferocytosis was assessed by flow cytometry and was expressed as MFI of CFSE-labeled neutrophils in $\mathrm{F} 4 / 80^{+}$cells. Representative histograms are shown in (A). To determine efferocytosis in vivo, $\mathrm{BALB} / \mathrm{c}$ mice received an i.p. injection of $0.1 \mathrm{mg}$ of zymosan and $62 \mathrm{~h}$ later were injected i.p. with db-cAMP $(4 \mathrm{mg} / \mathrm{kg})$ or PBS. Seven hours after the treatment, mice received an i.p. injection of $10^{6}$ apoptotic human neutrophils labeled with CFSE. The cells from the peritoneal cavity were collected $1 \mathrm{~h}$ later. Efferocytosis was assessed in macrophages by flow cytometry according to their size and granularity, expression of the surface molecule F4/80, and intracellular CFSE (D,E), as described in the gating strategy (F). Results are expressed as $\%$ of MØ F4/80 $0^{+} \mathrm{CFSE}^{+}$(D) or MFI of CFSE-labeled neutrophils in $\mathrm{F} 4 / 80^{+}$cells (E) of 6-7 mice in each group. Efferocytosis was also investigated by morphological counting of cytospin slides stained with May-Grunwald-Giemsa (G,H). In $\mathbf{H}$, arrows indicate apoptotic neutrophils inside macrophages. Magnification 40x. Results are shown as the mean $\pm \mathrm{SEM}^{*} p<0.05, * * * p<0.001$, when compared with PBS-injected mice. 

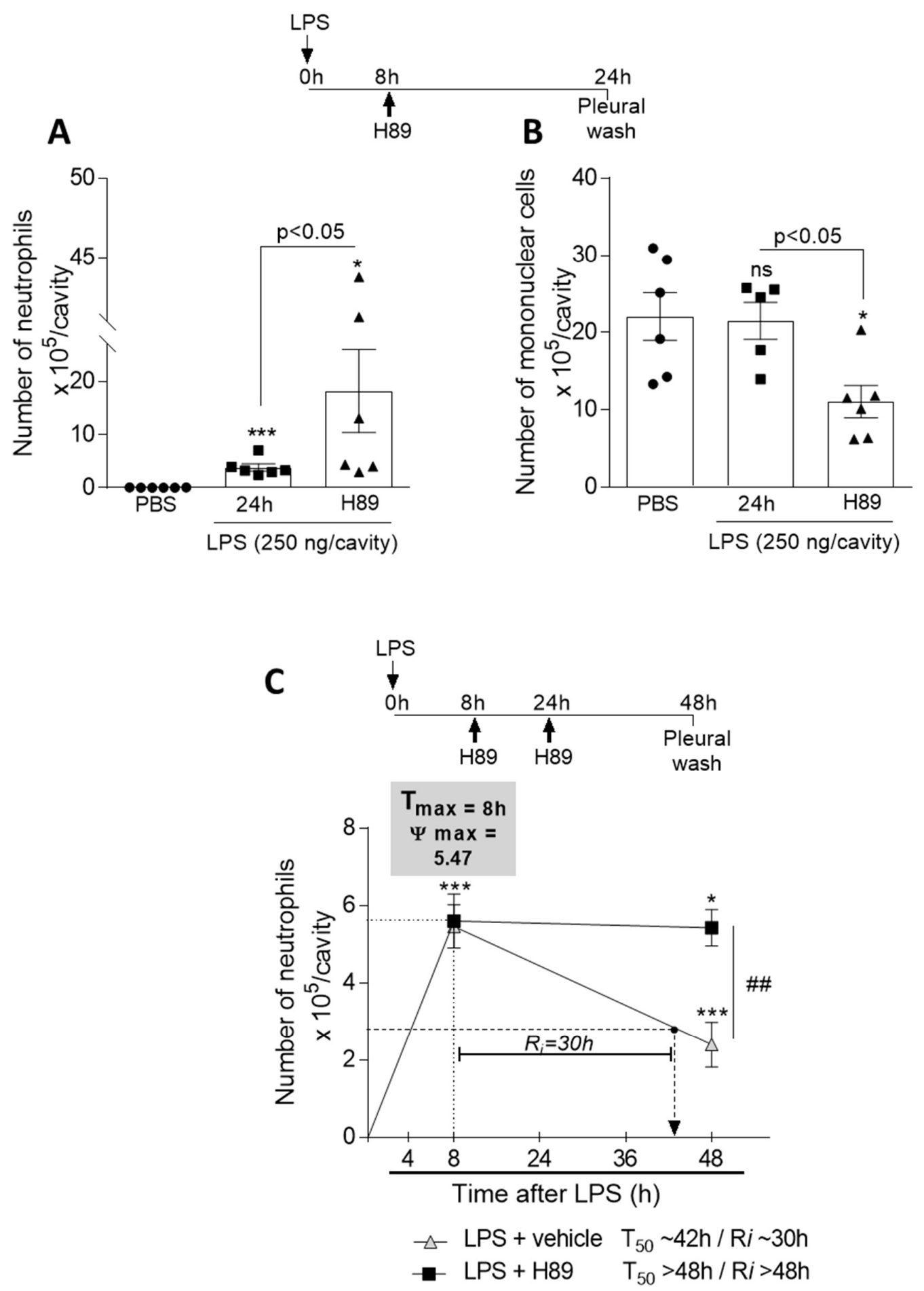

Figure 7. Effect of PKA inhibition in a self-resolving model of inflammation. BALB/c mice were injected with LPS (250 ng/cavity, i.pl.) or PBS, and $8 \mathrm{~h}$ later received an injection of H89 (4 mg/kg, i.pl.). Cells present in the pleural cavity were harvested $24 \mathrm{~h}$ after LPS challenge or PBS injection for neutrophil (A) and mononuclear cells (B) counts. In (C) mice were injected with LPS (250 ng/cavity, i.pl.) or PBS, and 8 and $24 \mathrm{~h}$ later received an injection of $\mathrm{H} 89$ ( $4 \mathrm{mg} / \mathrm{kg}$, i.pl.). Cells present in the pleural cavity were harvested $8 \mathrm{~h}$ and $48 \mathrm{~h}$ after LPS challenge or PBS injection and neutrophils were counted from cytospin preparations to calculate resolution indices. Results are shown as the mean \pm SEM of 5-7 mice in each group. ${ }^{*} p<0.05,{ }^{* * *} p<0.001$, when compared with PBS-injected group. 


\section{Discussion}

Cyclic AMP is a second messenger that has multiple roles in cell physiology and exerts general modulating effects on a variety of cells. In the immune system, cAMP regulates the activities of innate and adaptive immune cells [27], showing the importance of cAMP in modulating inflammation. In the current study, by using db-cAMP (a cell permeable cAMP mimetic) we have shown that $\mathrm{db}$-cAMP (i) induces nonphlogistic monocyte recruitment in vivo (depending on PKA and CCR2 signaling); (ii) induces macrophage polarization toward an M2 anti-inflammatory phenotype in vitro (depending on PKA) and has a synergistic effect with IL-4 on macrophage polarization to M2 phenotype; (iii) re-educates macrophages induced by IFN- $\gamma /$ LPS toward an M2-like phenotype; (iv) decreases the number of M1 macrophages induced by LPS-injection and increases the frequency of cells expressing molecules involved with recognition of apoptotic cells and engulfment; (v) promotes efferocytosis of apoptotic neutrophils in vitro (depending on PKA) and in vivo; and that (vi) cAMP is an endogenous determinant of the physiological resolution of LPS-induced pleurisy. Therefore, we provide evidence that cAMP regulate key macrophage functions by regulating nonphlogistic monocyte migration, reprogramming macrophages, and promoting efferocytosis (Figure 8).

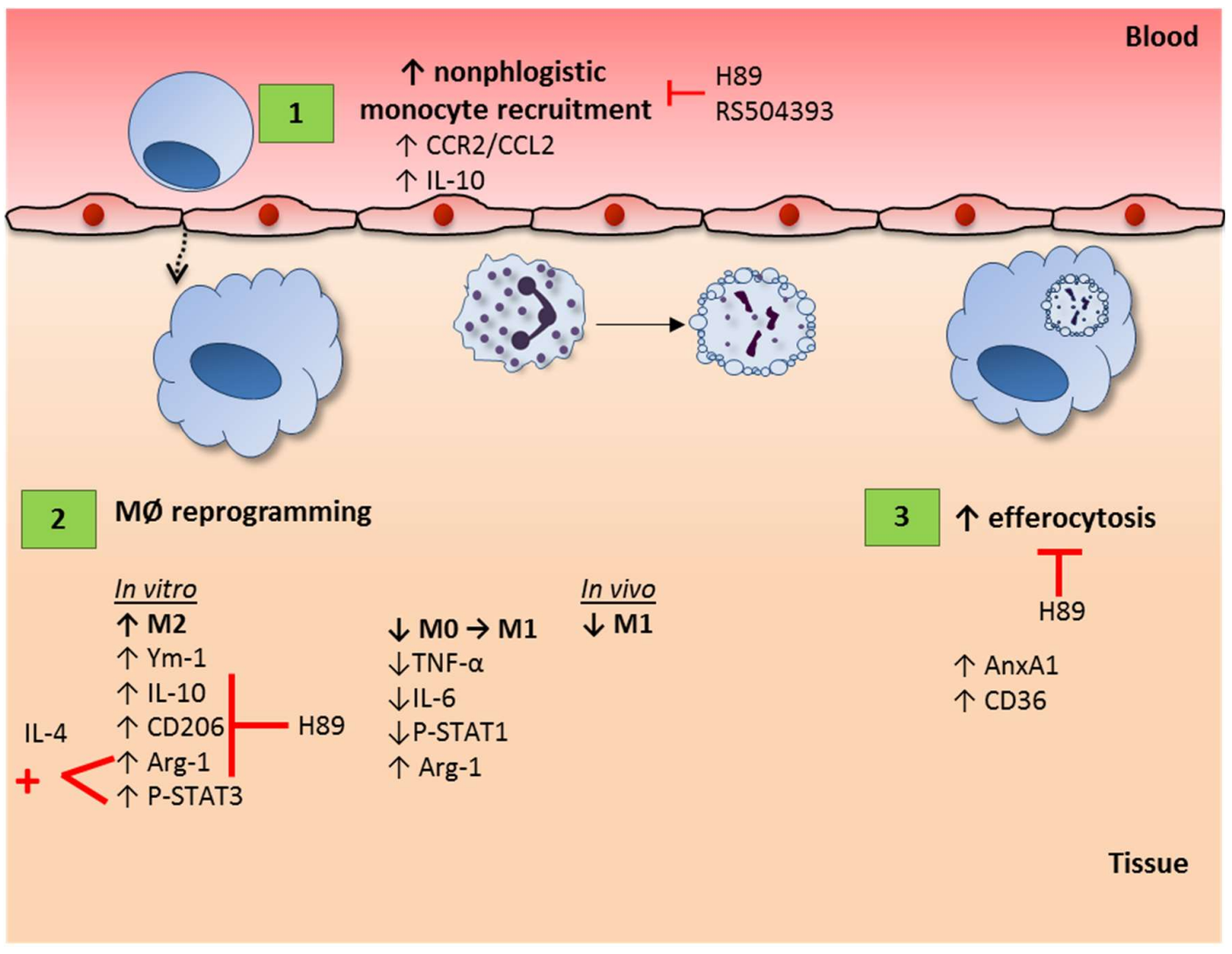

Figure 8. Schematic representation of the effects of cAMP on macrophage features. Our data show that cAMP induces monocyte recruitment in a PKA- andCCR2-dependent manner (1). We also demonstrate that cAMP promote macrophage polarization to the M2 profile in a PKA-dependent manner, while skew IFN- $\gamma /$ LPS polarization to M2 phenotypes (2). Moreover, cAMP synergizes with IL-4 to promote M2 markers in macrophages. In addition, we demonstrate that cAMP promote the expression of engulfment-molecules and increases the efferocytic capacity of macrophages in a PKA-dependent manner (3). The pro-resolving effects summarized herein (1-3) have been described for db-cAMP, a cAMP mimetic, and can account for the endogenous role of cAMP in physiological resolution of inflammation. Note: Red lines represent inhibition effect.

Recruitment of monocytes that differentiate into macrophages at inflammatory sites is a hallmark of inflammation resolution [3,70]. These cells promote clearance of the neutrophilic infiltrate, and therefore 
rescue apoptotic neutrophils from evolving to a necrotic state, what would contribute to amplify the pro-inflammatory process [8]. A recent study showed that rolipram, a PDE4 inhibitor, which increases the intracellular cAMP levels, induces chemotaxis of macrophages previously stimulated with LPS [71]. Here, we demonstrated that db-cAMP by itself was able to induce nonphlogistic monocyte migration, which may contribute to the pro-resolving properties of this molecule (Figure 7 and references [32-34]). Importantly db-cAMP-induced leukocyte migration was selective for monocytes, without causing neutrophil recruitment or pro-inflammatory cytokine/chemokine production, at least at the time points evaluated herein. In addition, mononuclear cell recruitment was accompanied by increased levels of the anti-inflammatory cytokine IL-10. Indeed, molecules that play proresolving actions such as AnxA1 [39,40,72], lipoxin A4 [73,74] and plasminogen/plasmin [46,75] are able to induce nonphlogistic macrophage recruitment contributing to the resolution of inflammation.

CCR2 receptor is involved in both migration of bone marrow monocytes into the bloodstream [53] and in the migration of mononuclear cells from blood to tissues [76]. Several cell types, including endothelial, mesothelial, fibroblasts, epithelial, smooth muscle, mesangial, astrocytes, monocytes/ macrophages, and microglial cells [77-81], produce CCR2 receptor ligand CCL2 chemokine. CCL2, in turn, is responsible to regulating monocyte recruitment and activation of T lymphocyte subpopulations $[82,83]$. Indeed, Cailhier et al. have suggested that mesothelial cells are responsible for the production of this chemokine in the model of carrageenan-induced pleurisy [84]. Here, we have shown that db-cAMP induces early CCL2 production into the pleural cavity, which precedes monocyte recruitment. Thus, our hypothesis is that the detected CCL2 is produced by resident pleural cells, as in the study of Cailhier et al. [84]. By contrast, Motoyoshi and colleagues demonstrated that forskolin, an adenylyl cyclase inducer, decreased CCL2 levels induced by S100B, a RAGE receptor-binding protein involved on development of autoimmune and inflammatory diseases [85]. However, to the best of our knowledge, the present study is the first to demonstrate the participation of cAMP in CCR2/CCL2 pathway for monocyte recruitment in a non-inflammatory context. Together, the results of our work and the previous study [85] point to a dual role of cAMP in CCL2 production. In a phlogistic context of an ongoing inflammatory process, as shown by Motoyoshi, where there is an initial stimulus for migration of inflammatory monocytes/macrophages, increased cAMP levels may act reducing the CCL2 levels and limiting the inflammatory process [85]. One the other hand, cAMP may activate the CCL2/CCR2 axis, such as during the resolving phase of inflammation, and induce nonphlogistic monocyte recruitment, which may contribute to the resolution process. Thus, the effect of cAMP on monocyte migration seems to depend on the phase of inflammation, having divergent action at the onset and resolving phases of inflammation. In both cases, the outcome is the modulation of the inflammatory process favoring the resolution of inflammation.

Macrophages are plastic cells that differ according to the microenvironment and may assume different phenotypes in vivo and in vitro depending on the stimulus. Macrophage phenotypes are generally divided in M1 and M2 (M2a, M2b and M2c), also known as classically and alternatively activated macrophages, respectively. IFN- $\gamma$, LPS and TNF induce M1-like pro-inflammatory phenotypes, whereas the M2-like anti-inflammatory phenotype is induced by IL4/IL13 (M2a), immune complexes (M2b) and IL-10 or TGF- $\beta$ (M2c) [86-89]. The production of cAMP by resolution phase macrophages (rMs), but not chronic inflammatory macrophages, was introduced by Bystrom and colleagues in 2008. Db-cAMP was able to transform M1-like macrophages to rMs-like cells [29]. Later, another study demonstrated that 8-Br-cAMP, another cAMP analogue, induces Arg-1 expression in RAW 264.7 murine macrophages, being the first to suggest the direct participation of cAMP in macrophage polarization [31]. Here, we have shown that db-cAMP induced not only Arg-1, but also other M2 markers such as CD206, Ym-1 and IL-10 in BMDMs and RAW 264.7 cells, demonstrating more robustly that, in fact, cAMP is involved in macrophage polarization to an M2-like phenotype. Corroborating with our data, a recent study demonstrated in the experimental autoimmune encephalitis (EAE) model that forskolin increases M2 (Arg1, Mrc1, Fizz1 and Ym1) and decreases M1 (NOS2 and CD86) markers dependent on the ERK signaling pathway [30]. However, it is important to note that 
in our experimental settings db-cAMP also induced iNOS expression at low range as compared to IFN- $\gamma /$ LPS (compare Figures $2 \mathrm{C}$ and $4 \mathrm{~B}$ ), without impacting TNF- $\alpha$ levels, suggesting that db-cAMP and forskolin reprogram macrophages towards different profiles. The expression of iNOS is a mechanism associated with bacterial clearance, through the production of nitric oxide, a free radical that has bactericidal capacity [90]. Therefore, the mixed profile of macrophages induced by db-cAMP in the present study, composed by macrophages with both profiles, containing anti-inflammatory markers and the pro-inflammatory marker (iNOs), the latter known for its bactericidal capacity, might be important for the resolution of infectious inflammation. Indeed, our group demonstrated that PDE4 inhibition by rolipram increases bacterial phagocytosis during the late phase of infection [91], thus corroborating our hypothesis.

Signal transducers and activators of transcription proteins (STATs) transmit signaling of many inducers of the M1 and M2 macrophage phenotypes. IFN- $\gamma / \mathrm{LPS}$ treatment induces macrophage polarization to the M1-like phenotype via STAT1, while IL-4 induces macrophage polarization to the M2-like phenotype via STAT6 (canonical pathway) and STAT3 (non-canonical pathway) [92]. Sheldon and colleagues showed that 8-Br-cAMP has a synergistic effect with IL-4 on Arg-1 and STAT6 expression [31]. Interestingly, here we demonstrated that db-cAMP induced transient STAT3 phosphorylation and had a synergistic effect with IL-4 on STAT3 phosphorylation and Arg-1 expression. Although in our experimental conditions changes in p-STAT6 levels were not detected after db-cAMP stimulation, we cannot exclude the participation of STAT6 in this process. Corroborating our data, Koscso and colleagues demonstrated that adenosine, which binds to A2A and A2B receptors and stimulate the adenylyl cyclase to produce cAMP, has synergistic effect with IL-10 in inducing macrophage polarization towards an M2c profile in a STAT3-dependent manner [93]. Moreover, recent studies have argued that STAT3 activation can occur via PKA [94,95]. Although we have not investigated here whether db-cAMP-induced STAT3 activation was via PKA, we can hypothesize that PKA activation may be occurring in our settings of macrophage reprogramming.

Importantly, a study demonstrated that prostaglandin E2 (PGE2), a cAMP elevator, activates PKA, which inhibits SIK2 (a salt-inducible kinase) and, in turn, prevents the phosphorylation of CREB-regulated transcription coactivator (CRTC3) [96]. This allows the dephosphorylation of SIK2 sites on CRTC3, resulting in the translation of the later to the nucleus [96]. Once inside the nucleus, CRTC3 can interact with CREB (cAMP response element-binding) to promote CREB-dependent gene transcription, which in macrophages includes the IL-10 gene involved in macrophage polarization to an anti-inflammatory (M2) profile [96,97]. Moreover, the clinically approved drugs bosutinib and dasatinib promote macrophage polarization, characterized by the production of high levels of IL-10 and very low levels of pro-inflammatory cytokines, by inhibiting SIKs through CRTC3 dephosphorylation and inducing CREB-dependent gene transcription [98]. Interestingly, pharmacological or genetic inhibition of SIKs also leads to CRTC3 dephosphorylation in macrophages with further CRTC3 translocation to the nucleus, where it acts as a co-factor for CREB-dependent gene transcription, including transcription of IL-10 and markers of regulatory-like macrophages (M2b), such as SPHK1, LIGHT and Arg-1 [99]. These studies provide important evidence of the role of PKA in reprogramming macrophages and corroborate our data that increased IL-10 levels induced by db-cAMP occur via PKA. Taking all these studies into account, we can suggest that the rapid db-cAMP-induced STAT3 phosphorylation found in our study (Figure $3 \mathrm{~A}$ ) might be occurring through $\mathrm{CAMP} \rightarrow \mathrm{PKA} \rightarrow \mathrm{CREB}$ activation, which can, in turn, increases IL-10 levels. Whether SIKs are involved in this process will require further investigation.

As the inflammatory response evolves, macrophages change their phenotype from M1 to M2 and then to Mres, a key process for resolving inflammation $[3,10,100,101]$. We have shown here that db-cAMP increased Arg-1 expression, reduced pro-inflammatory cytokine levels (TNF- $\alpha$ and IL-6) and STAT1 phosphorylation in BMDMs in the presence of M1 stimulus (IFN- $\gamma / \mathrm{LPS}$ ), indicating that db-cAMP can skew the macrophage phenotype induced by IFN- $\gamma /$ LPS to the M2 phenotype. Corroborating with our in vitro data, db-cAMP also decreased the number of LPS-induced M1 macrophages in vivo without affecting the number of M2 and Mres macrophages. In an experimental model of autoimmune 
encephalomyelitis (EAE), an inflammatory disease of the central nervous system where both M1 (IFN- $\gamma$ ) and M2 (IL-4) cytokines are present, forskolin deviates this balance favoring the M2 phenotype [30], suggesting that cAMP-induced polarization might depend on the microenvironment.

Efferocytosis is a hallmark for homeostasis and resolution of inflammation and is characterized by phagocytosis of apoptotic cells [102]. Apoptotic cell clearance has profound effects on immune and adaptive responses in inflamed tissues [66]. It has been shown that pro-resolving mediators that are known to increase cAMP levels, such as melanocortins, are inducers of efferocytosis [103]. In addition, increased levels of cAMP and PGE2, one of the major lipid mediator synthesized by macrophages during the inflammatory response, induced by lysophosphatidylserine (lysoPS) binding expressed on apoptotic neutrophils are involved in efferocytosis, signaling through increased activity of Rac1, dependent on PKA [104-106]. There are some key molecules well known to be involved with macrophage efferocytosis. AnxA1, a protein with pro-resolving properties, which was previously shown to be induced by cAMP, is produced by both macrophages and neutrophils, facilitating apoptotic neutrophil efferocytosis [107]. In addition, several studies have shown the participation of AnxA1 in efferocytosis [45,58-62]. Another molecule involved in macrophage mediated efferocytosis is the CD36 receptor, which recognizes lipid ligands present on the surface of apoptotic cells $[57,108]$ contributing to the modulation of efferocytosis [57,63-65]. In the present work, we have identified that db-cAMP increases the percentage of cells expressing AnxA1 and CD36 during LPS-induced pleurisy model, adding to the understanding of the molecular events involved in cAMP-induced efferocytosis.

In accordance with the increased expression of engulfment-molecules in macrophages treated with db-cAMP, we found that db-cAMP could indeed promote efferocytosis, in vitro and in vivo. Mechanistically, we have shown in BMDMs that db-cAMP increases efferocytosis of apoptotic neutrophils in a PKA-dependent manner. Similarly, we demonstrated that db-cAMP was also able to increase efferocytosis in vivo. In contrast, Rossi and colleagues demonstrated that PGE2, PGD2, $\mathrm{db}$-cAMP and 8-bromo-cAMP decreased macrophage-mediated neutrophil efferocytosis of human monocytes [109], but treatments were performed just for $15 \mathrm{~min}$. Therefore, we suggest that a more prolonged treatment time seems to be essential for macrophage capacitation by increasing the expression of molecules involved on recognition and engulfment processes, as demonstrated by the increased AnxA1 and CD36 in our study.

The effects of db-cAMP on monocyte recruitment, polarization and efferocytosis were shown to occur in a PKA-dependent manner, as the PKA inhibitor H89 was able to inhibit db-cAMP-induced effects. PKA is the best known and most studied cAMP effector protein [26,27]. cAMP binds directly to PKA promoting rearrangements that favors enzymatic activity [26,27]. Among other actions, PKA mediates the inhibition of inflammatory mediator production in macrophages [110]. Indeed, inhibition of PKA by H89 limits the cAMP-mediated resolution of acute inflammation [33,34]. H89 was also able to inhibit db-cAMP and rolipram-induced effects such as increased AnxA1 expression in THP-1 cells and resolution of inflammation in the LPS-induced pleurisy model [32]. Here, akin with previous data obtained by administrating pharmacological compounds that raises the intracellular levels of cAMP, such as rolipram and Forskolin [34], we have shown that endogenous cAMP works as a branch to counter-regulate the inflammatory process, since its inhibition by using H89 hampered the spontaneous resolution of inflammation.

It has been reported that cAMP is an important intracellular molecule that conveys the signals of several pro-resolving mediators, such as RvD1, RvD2, melanocortin and AnxA1 [32,35-38]. The list of molecules bearing pro-resolving actions is continuously growing, as recently described for plasmin $[45,46,75]$ and IFN- $\beta$ [111], well known molecules only recently shown to affect several steps of resolution, such as monocyte migration, macrophage reprogramming, efferocytosis and neutrophil apoptosis. Whether db-cAMP function as an intracellular mediator or an inductor of these newly described pro-resolving molecules deserves further investigation.

In conclusion, the present study adds contribution to the current knowledge of the effects of cAMP on resolution of inflammation [32-34], showing that db-cAMP induces proresolving properties 
in macrophages (summarized in Figure 8), such as nonphlogistic recruitment, reprogramming and efferocytosis, which are key processes for resolving inflammation.

Supplementary Materials: The following are available online at http://www.mdpi.com/2073-4409/9/1/128/s1, Figure S1: Effects of db-cAMP on Ym-1 expression, Figure S2: Effect of db-cAMP on polarization of RAW 264.7, Figure S3: Gating scheme and representative dot plots and histograms showing the effect of db-cAMP on macrophage polarization of LPS-inflamed mice.

Author Contributions: Conceptualization, L.P.S., M.A.S., K.M.L. and G.L.N.-L.; Methodology, G.L.N.-L., K.M.L.; I.Z.M., B.L.O.J., J.P.V., L.C.R.T., I.G. and M.A.S.; Validation, G.L.N.-L. and K.M.L. Formal Analysis, L.P.S., G.L.N.-L., K.M.L, M.A.S., J.P.V. and I.G.; Investigation L.P.S., M.A.S., G.L.N.-L. and K.M.L.; Writing-Original Draft Preparation, G.L.N.-L. and K.M.L.; Writing-Review \& Editing, L.P.S., G.L.N.-L., M.A.S., J.P.V., V.P. and M.M.T.; Supervision, L.P.S. and M.A.S.; Project Administration, L.P.S.; Funding Acquisition, L.P.S., V.P. and M.M.T. All authors have read and agreed to the published version of the manuscript.

Funding: This work was supported by grants from Conselho Nacional de Desenvolvimento Científico e Tecnológico (CNPq, Brazil), Fundação de Amparo à Pesquisa do Estado de Minas Gerais (FAPEMIG, Brazil), Pró-Reitoria de Pesquisa da Universidade Federal de Minas Gerais-PRPq, Brazil, and Coordenação de Aperfeiçoamento de Pessoal de Nível Superior (CAPES).

Acknowledgments: We would like to thank Rosemeire Oliveira and Ilma Marçal for technical assistance.

Conflicts of Interest: The authors declare no conflict of interest.

\section{References}

1. Fullerton, J.N.; Gilroy, D.W. Resolution of inflammation: A new therapeutic frontier. Nat. Rev. Drug Discov. 2016, 15, 551-567. [CrossRef] [PubMed]

2. Serhan, C.N.; Brain, S.D.; Buckley, C.D.; Gilroy, D.W.; Haslett, C.; O’Neill, L.A.; Perretti, M.; Rossi, A.G.; Wallace, J.L. Resolution of inflammation: State of the art, definitions and terms. FASEB J. 2007, 21, 325-332. [CrossRef] [PubMed]

3. Sugimoto, M.A.; Vago, J.P.; Perretti, M.; Teixeira, M.M. Mediators of the Resolution of the Inflammatory Response. Trends Immunol. 2019, 40, 212-227. [CrossRef] [PubMed]

4. Medzhitov, R. Inflammation 2010: New adventures of an old flame. Cell 2010, 140, 771-776. [CrossRef] [PubMed]

5. Feehan, K.T.; Gilroy, D.W. Is Resolution the End of Inflammation? Trends Mol. Med. 2019, 25, $198-214$. [CrossRef] [PubMed]

6. Nathan, C.; Ding, A. Nonresolving inflammation. Cell 2010, 140, 871-882. [CrossRef]

7. Hallett, J.M.; Leitch, A.E.; Riley, N.A.; Duffin, R.; Haslett, C.; Rossi, A.G. Novel pharmacological strategies for driving inflammatory cell apoptosis and enhancing the resolution of inflammation. Trends Pharmacol. Sci. 2008, 29, 250-257. [CrossRef]

8. Poon, I.K.; Lucas, C.D.; Rossi, A.G.; Ravichandran, K.S. Apoptotic cell clearance: Basic biology and therapeutic potential. Nat. Rev. Immunol. 2014, 14, 166-180. [CrossRef]

9. Labonte, A.C.; Tosello-Trampont, A.C.; Hahn, Y.S. The role of macrophage polarization in infectious and inflammatory diseases. Mol. Cells 2014, 37, 275-285. [CrossRef]

10. Ariel, A.; Serhan, C.N. New Lives Given by Cell Death: Macrophage Differentiation Following Their Encounter with Apoptotic Leukocytes during the Resolution of Inflammation. Front. Immunol. 2012, 3, 4. [CrossRef]

11. Lichtnekert, J.; Kawakami, T.; Parks, W.C.; Duffield, J.S. Changes in macrophage phenotype as the immune response evolves. Curr. Opin. Pharmacol. 2013, 13, 555-564. [CrossRef] [PubMed]

12. Schif-Zuck, S.; Gross, N.; Assi, S.; Rostoker, R.; Serhan, C.N.; Ariel, A. Saturated-efferocytosis generates pro-resolving CD11b low macrophages: Modulation by resolvins and glucocorticoids. Eur. J. Immunol. 2011, 41, 366-379. [CrossRef] [PubMed]

13. Mills, C.D.; Harris, R.A.; Ley, K. Macrophage Polarization: Decisions That Affect Health. J. Clin. Cell Immunol. 2015, 6. [CrossRef]

14. Lee, C.H.; Kim, Y.J.; Jang, J.H.; Park, J.W. Modulating macrophage polarization with divalent cations in nanostructured titanium implant surfaces. Nanotechnology 2016, 27, 085101. [CrossRef] [PubMed] 
15. Jain, S.; Tran, T.H.; Amiji, M. Macrophage repolarization with targeted alginate nanoparticles containing IL-10 plasmid DNA for the treatment of experimental arthritis. Biomaterials 2015, 61, 162-177. [CrossRef] [PubMed]

16. Martinez, F.O. Regulators of macrophage activation. Eur. J. Immunol. 2011, 41, 1531-1534. [CrossRef]

17. Fadok, V.A.; Bratton, D.L.; Konowal, A.; Freed, P.W.; Westcott, J.Y.; Henson, P.M. Macrophages that have ingested apoptotic cells in vitro inhibit proinflammatory cytokine production through autocrine/paracrine mechanisms involving TGF-beta, PGE2, and PAF. J. Clin. Investig. 1998, 101, 890-898. [CrossRef]

18. Korns, D.; Frasch, S.C.; Fernandez-Boyanapalli, R.; Henson, P.M.; Bratton, D.L. Modulation of macrophage efferocytosis in inflammation. Front. Immunol. 2011, 2, 57. [CrossRef]

19. Voll, R.E.; Herrmann, M.; Roth, E.A.; Stach, C.; Kalden, J.R.; Girkontaite, I. Immunosuppressive effects of apoptotic cells. Nature 1997, 390, 350-351. [CrossRef]

20. Freire-de-Lima, C.G.; Xiao, Y.Q.; Gardai, S.J.; Bratton, D.L.; Schiemann, W.P.; Henson, P.M. Apoptotic cells, through transforming growth factor-beta, coordinately induce anti-inflammatory and suppress pro-inflammatory eicosanoid and NO synthesis in murine macrophages. J. Biol. Chem. 2006, 281, 38376-38384. [CrossRef]

21. Wang, Y.; Lin, Y.X.; Qiao, S.L.; An, H.W.; Ma, Y.; Qiao, Z.Y.; Rajapaksha, R.P.; Wang, H. Polymeric nanoparticles promote macrophage reversal from M2 to M1 phenotypes in the tumor microenvironment. Biomaterials 2017, 112, 153-163. [CrossRef] [PubMed]

22. Vidyarthi, A.; Khan, N.; Agnihotri, T.; Negi, S.; Das, D.K.; Aqdas, M.; Chatterjee, D.; Colegio, O.R.; Tewari, M.K.; Agrewala, J.N. TLR-3 Stimulation Skews M2 Macrophages to M1 Through IFN- $\alpha \beta$ Signaling and Restricts Tumor Progression. Front. Immunol. 2018, 9, 1650. [CrossRef] [PubMed]

23. Laskin, D.L.; Sunil, V.R.; Gardner, C.R.; Laskin, J.D. Macrophages and tissue injury: Agents of defense or destruction? Annu. Rev. Pharmacol. Toxicol. 2011, 51, 267-288. [CrossRef] [PubMed]

24. Mills, C.D.; Kincaid, K.; Alt, J.M.; Heilman, M.J.; Hill, A.M. M-1/M-2 macrophages and the Th1/Th2 paradigm. J. Immunol. 2000, 164, 6166-6173. [CrossRef] [PubMed]

25. Miao, X.; Leng, X.; Zhang, Q. The Current State of Nanoparticle-Induced Macrophage Polarization and Reprogramming Research. Int. J. Mol. Sci. 2017, 18, 336. [CrossRef]

26. Gerlo, S.; Kooijman, R.; Beck, I.M.; Kolmus, K.; Spooren, A.; Haegeman, G. Cyclic AMP: A selective modulator of NF-kB action. Cell. Mol. Life Sci. 2011, 68, 3823-3841. [CrossRef]

27. Raker, V.K.; Becker, C.; Steinbrink, K. The cAMP Pathway as Therapeutic Target in Autoimmune and Inflammatory Diseases. Front. Immunol. 2016, 7, 123. [CrossRef]

28. Stables, M.J.; Newson, J.; Ayoub, S.S.; Brown, J.; Hyams, C.J.; Gilroy, D.W. Priming innate immune responses to infection by cyclooxygenase inhibition kills antibiotic-susceptible and -resistant bacteria. Blood 2010, 116, 2950-2959. [CrossRef]

29. Bystrom, J.; Evans, I.; Newson, J.; Stables, M.; Toor, I.; van Rooijen, N.; Crawford, M.; Colville-Nash, P.; Farrow, S.; Gilroy, D.W. Resolution-phase macrophages possess a unique inflammatory phenotype that is controlled by cAMP. Blood 2008, 112, 4117-4127. [CrossRef]

30. Veremeyko, T.; Yung, A.W.Y.; Dukhinova, M.; Kuznetsova, I.S.; Pomytkin, I.; Lyundup, A.; Strekalova, T.; Barteneva, N.S.; Ponomarev, E.D. Cyclic AMP Pathway Suppress Autoimmune Neuroinflammation by Inhibiting Functions of Encephalitogenic CD4 T Cells and Enhancing M2 Macrophage Polarization at the Site of Inflammation. Front. Immunol. 2018, 9, 50. [CrossRef]

31. Sheldon, K.E.; Shandilya, H.; Kepka-Lenhart, D.; Poljakovic, M.; Ghosh, A.; Morris, S.M. Shaping the murine macrophage phenotype: IL-4 and cyclic AMP synergistically activate the arginase I promoter. J. Immunol. 2013, 191, 2290-2298. [CrossRef] [PubMed]

32. Lima, K.M.; Vago, J.P.; Caux, T.R.; Negreiros-Lima, G.L.; Sugimoto, M.A.; Tavares, L.P.; Arribada, R.G.; Carmo, A.A.F.; Galvão, I.; Costa, B.R.C.; et al. The resolution of acute inflammation induced by cyclic AMP is dependent on annexin A1. J. Biol. Chem. 2017, 292, 13758-13773. [CrossRef] [PubMed]

33. Sousa, L.P.; Carmo, A.F.; Rezende, B.M.; Lopes, F.; Silva, D.M.; Alessandri, A.L.; Bonjardim, C.A.; Rossi, A.G.; Teixeira, M.M.; Pinho, V. Cyclic AMP enhances resolution of allergic pleurisy by promoting inflammatory cell apoptosis via inhibition of PI3K/Akt and NF-kappaB. Biochem. Pharmacol. 2009, 78, 396-405. [CrossRef] [PubMed] 
34. Sousa, L.P.; Lopes, F.; Silva, D.M.; Tavares, L.P.; Vieira, A.T.; Rezende, B.M.; Carmo, A.F.; Russo, R.C.; Garcia, C.C.; Bonjardim, C.A.; et al. PDE4 inhibition drives resolution of neutrophilic inflammation by inducing apoptosis in a PKA-PI3K/Akt-dependent and NF-kappaB-independent manner. J. Leukoc. Biol. 2010, 87, 895-904. [CrossRef]

35. Chiang, N.; Dalli, J.; Colas, R.A.; Serhan, C.N. Identification of resolvin D2 receptor mediating resolution of infections and organ protection. J. Exp. Med. 2015, 212, 1203-1217. [CrossRef]

36. Lee, H.N.; Surh, Y.J. Resolvin D1-mediated NOX2 inactivation rescues macrophages undertaking efferocytosis from oxidative stress-induced apoptosis. Biochem. Pharmacol. 2013, 86, 759-769. [CrossRef]

37. Montero-Melendez, T.; Patel, H.B.; Seed, M.; Nielsen, S.; Jonassen, T.E.; Perretti, M. The melanocortin agonist AP214 exerts anti-inflammatory and proresolving properties. Am. J. Pathol. 2011, 179, 259-269. [CrossRef]

38. Patruno, S.; Garrido-Mesa, J.; Romano, M.; Perretti, M.; Montero-Melendez, T. Ligand Bias and Its Association With Pro-resolving Actions of Melanocortin Drugs. Front. Pharmacol. 2018, 9, 919. [CrossRef]

39. Sugimoto, M.A.; Vago, J.P.; Teixeira, M.M.; Sousa, L.P. Annexin A1 and the Resolution of Inflammation: Modulation of Neutrophil Recruitment, Apoptosis, and Clearance. J. Immunol. Res. 2016, 2016, 8239258. [CrossRef] [PubMed]

40. Perucci, L.O.; Sugimoto, M.A.; Gomes, K.B.; Dusse, L.M.; Teixeira, M.M.; Sousa, L.P. Annexin A1 and specialized proresolving lipid mediators: Promoting resolution as a therapeutic strategy in human inflammatory diseases. Expert Opin. Ther. Targets 2017, 21, 879-896. [CrossRef]

41. García-Osta, A.; Cuadrado-Tejedor, M.; García-Barroso, C.; Oyarzábal, J.; Franco, R. Phosphodiesterases as therapeutic targets for Alzheimer's disease. ACS Chem. Neurosci. 2012, 3, 832-844. [CrossRef] [PubMed]

42. Schafer, P.H.; Day, R.M. Novel systemic drugs for psoriasis: Mechanism of action for apremilast, a specific inhibitor of PDE4. J. Am. Acad. Dermatol. 2013, 68, 1041-1042. [CrossRef] [PubMed]

43. Wittmann, M.; Helliwell, P.S. Phosphodiesterase 4 inhibition in the treatment of psoriasis, psoriatic arthritis and other chronic inflammatory diseases. Dermatol Ther. (Heidelb.) 2013, 3, 1-15. [CrossRef] [PubMed]

44. Vago, J.P.; Nogueira, C.R.; Tavares, L.P.; Soriani, F.M.; Lopes, F.; Russo, R.C.; Pinho, V.; Teixeira, M.M.; Sousa, L.P. Annexin A1 modulates natural and glucocorticoid-induced resolution of inflammation by enhancing neutrophil apoptosis. J. Leukoc. Biol. 2012, 92, 249-258. [CrossRef]

45. Sugimoto, M.A.; Ribeiro, A.L.C.; Costa, B.R.C.; Vago, J.P.; Lima, K.M.; Carneiro, F.S.; Ortiz, M.M.O.; Lima, G.L.N.; Carmo, A.A.F.; Rocha, R.M.; et al. Plasmin and plasminogen induce macrophage reprogramming and regulate key steps of inflammation resolution via annexin A1. Blood 2017, 129, 2896-2907. [CrossRef]

46. Vago, J.P.; Sugimoto, M.A.; Lima, K.M.; Negreiros-Lima, G.L.; Baik, N.; Teixeira, M.M.; Perretti, M.; Parmer, R.J.; Miles, L.A.; Sousa, L.P. Plasminogen and the Plasminogen Receptor, Plg-R. Front. Immunol. 2019, 10, 1458. [CrossRef]

47. Bannenberg, G.L.; Chiang, N.; Ariel, A.; Arita, M.; Tjonahen, E.; Gotlinger, K.H.; Hong, S.; Serhan, C.N. Molecular circuits of resolution: Formation and actions of resolvins and protectins. J. Immunol. 2005, 174, 4345-4355. [CrossRef]

48. Vago, J.P.; Tavares, L.P.; Sugimoto, M.A.; Lima, G.L.; Galvão, I.; de Caux, T.R.; Lima, K.M.; Ribeiro, A.L.; Carneiro, F.S.; Nunes, F.F.; et al. Proresolving Actions of Synthetic and Natural Protease Inhibitors Are Mediated by Annexin A1. J. Immunol. 2016, 196, 1922-1932. [CrossRef]

49. Newson, J.; Stables, M.; Karra, E.; Arce-Vargas, F.; Quezada, S.; Motwani, M.; Mack, M.; Yona, S.; Audzevich, T.; Gilroy, D.W. Resolution of acute inflammation bridges the gap between innate and adaptive immunity. Blood 2014, 124, 1748-1764. [CrossRef]

50. Perez, D.A.; Galvão, I.; Athayde, R.M.; Rezende, B.M.; Vago, J.P.; Silva, J.D.; Reis, A.C.; Ribeiro, L.S.; Gomes, J.H.S.; Pádua, R.M.; et al. Inhibition of the sphingosine-1-phosphate pathway promotes the resolution of neutrophilic inflammation. Eur. J. Immunol. 2019. [CrossRef]

51. Ward, C.; Chilvers, E.R.; Lawson, M.F.; Pryde, J.G.; Fujihara, S.; Farrow, S.N.; Haslett, C.; Rossi, A.G. NF-kappaB activation is a critical regulator of human granulocyte apoptosis in vitro. J. Biol. Chem. 1999, 274, 4309-4318. [CrossRef] [PubMed]

52. Marim, F.M.; Silveira, T.N.; Lima, D.S.; Zamboni, D.S. A method for generation of bone marrow-derived macrophages from cryopreserved mouse bone marrow cells. PLoS ONE 2010, 5, e15263. [CrossRef] [PubMed] 
53. Serbina, N.V.; Pamer, E.G. Monocyte emigration from bone marrow during bacterial infection requires signals mediated by chemokine receptor CCR2. Nat. Immunol. 2006, 7, 311-317. [CrossRef] [PubMed]

54. Kuziel, W.A.; Morgan, S.J.; Dawson, T.C.; Griffin, S.; Smithies, O.; Ley, K.; Maeda, N. Severe reduction in leukocyte adhesion and monocyte extravasation in mice deficient in CC chemokine receptor 2. Proc. Natl. Acad. Sci. USA 1997, 94, 12053-12058. [CrossRef]

55. Malyshev, I.; Malyshev, Y. Current Concept and Update of the Macrophage Plasticity Concept: Intracellular Mechanisms of Reprogramming and M3 Macrophage "Switch" Phenotype. Biomed. Res. Int 2015, 2015, 341308. [CrossRef]

56. Vago, J.P.; Tavares, L.P.; Garcia, C.C.; Lima, K.M.; Perucci, L.O.; Vieira, É.; Nogueira, C.R.; Soriani, F.M.; Martins, J.O.; Silva, P.M.; et al. The role and effects of glucocorticoid-induced leucine zipper in the context of inflammation resolution. J. Immunol. 2015, 194, 4940-4950. [CrossRef]

57. Greenberg, M.E.; Sun, M.; Zhang, R.; Febbraio, M.; Silverstein, R.; Hazen, S.L. Oxidized phosphatidylserineCD36 interactions play an essential role in macrophage-dependent phagocytosis of apoptotic cells. J. Exp. Med. 2006, 203, 2613-2625. [CrossRef]

58. Yona, S.; Heinsbroek, S.E.; Peiser, L.; Gordon, S.; Perretti, M.; Flower, R.J. Impaired phagocytic mechanism in annexin 1 null macrophages. Br. J. Pharmacol. 2006, 148, 469-477. [CrossRef]

59. Scannell, M.; Flanagan, M.B.; deStefani, A.; Wynne, K.J.; Cagney, G.; Godson, C.; Maderna, P. Annexin-1 and peptide derivatives are released by apoptotic cells and stimulate phagocytosis of apoptotic neutrophils by macrophages. J. Immunol. 2007, 178, 4595-4605. [CrossRef]

60. McArthur, S.; Cristante, E.; Paterno, M.; Christian, H.; Roncaroli, F.; Gillies, G.E.; Solito, E. Annexin A1: A central player in the anti-inflammatory and neuroprotective role of microglia. J. Immunol. 2010, 185, 6317-6328. [CrossRef]

61. Maderna, P.; Cottell, D.C.; Toivonen, T.; Dufton, N.; Dalli, J.; Perretti, M.; Godson, C. FPR2/ALX receptor expression and internalization are critical for lipoxin A4 and annexin-derived peptide-stimulated phagocytosis. FASEB J. 2010, 24, 4240-4249. [CrossRef] [PubMed]

62. Dalli, J.; Montero-Melendez, T.; McArthur, S.; Perretti, M. Annexin A1 N-terminal derived Peptide ac2-26 exerts chemokinetic effects on human neutrophils. Front. Pharmacol. 2012, 3, 28. [CrossRef] [PubMed]

63. Driscoll, W.S.; Vaisar, T.; Tang, J.; Wilson, C.L.; Raines, E.W. Macrophage ADAM17 deficiency augments CD36-dependent apoptotic cell uptake and the linked anti-inflammatory phenotype. Circ. Res. 2013, 113, 52-61. [CrossRef]

64. Novak, M.L.; Thorp, E.B. Shedding light on impaired efferocytosis and nonresolving inflammation. Circ. Res. 2013, 113, 9-12. [CrossRef]

65. Parks, B.W.; Black, L.L.; Zimmerman, K.A.; Metz, A.E.; Steele, C.; Murphy-Ullrich, J.E.; Kabarowski, J.H. CD36, but not G2A, modulates efferocytosis, inflammation, and fibrosis following bleomycin-induced lung injury. J. Lipid Res. 2013, 54, 1114-1123. [CrossRef] [PubMed]

66. Elliott, M.R.; Koster, K.M.; Murphy, P.S. Efferocytosis Signaling in the Regulation of Macrophage Inflammatory Responses. J. Immunol. 2017, 198, 1387-1394. [CrossRef] [PubMed]

67. Rajakariar, R.; Newson, J.; Jackson, E.K.; Sawmynaden, P.; Smith, A.; Rahman, F.; Yaqoob, M.M.; Gilroy, D.W. Nonresolving inflammation in gp91phox-/- mice, a model of human chronic granulomatous disease, has lower adenosine and cyclic adenosine 5'-monophosphate. J. Immunol. 2009, 182, 3262-3269. [CrossRef] [PubMed]

68. Pederzoli-Ribeil, M.; Maione, F.; Cooper, D.; Al-Kashi, A.; Dalli, J.; Perretti, M.; D’Acquisto, F. Design and characterization of a cleavage-resistant Annexin A1 mutant to control inflammation in the microvasculature. Blood 2010, 116, 4288-4296. [CrossRef]

69. Chiang, N.; Shinohara, M.; Dalli, J.; Mirakaj, V.; Kibi, M.; Choi, A.M.; Serhan, C.N. Inhaled carbon monoxide accelerates resolution of inflammation via unique proresolving mediator-heme oxygenase-1 circuits. J. Immunol. 2013, 190, 6378-6388. [CrossRef]

70. Dalli, J.; Serhan, C.N. Pro-Resolving Mediators in Regulating and Conferring Macrophage Function. Front. Immunol. 2017, 8, 1400. [CrossRef]

71. Yang, J.X.; Hsiung, T.C.; Weng, F.C.; Ding, S.L.; Wu, C.P.; Conti, M.; Chuang, T.H.; Catherine Jin, S.L. Synergistic effect of phosphodiesterase 4 inhibitor and serum on migration of endotoxin-stimulated macrophages. Innate Immun. 2018, 24, 501-512. [CrossRef] [PubMed] 
72. McArthur, S.; Gobbetti, T.; Kusters, D.H.; Reutelingsperger, C.P.; Flower, R.J.; Perretti, M. Definition of a Novel Pathway Centered on Lysophosphatidic Acid To Recruit Monocytes during the Resolution Phase of Tissue Inflammation. J. Immunol. 2015, 195, 1139-1151. [CrossRef] [PubMed]

73. Maddox, J.F.; Serhan, C.N. Lipoxin A4 and B4 are potent stimuli for human monocyte migration and adhesion: Selective inactivation by dehydrogenation and reduction. J. Exp. Med. 1996, 183, 137-146. [CrossRef]

74. Maddox, J.F.; Hachicha, M.; Takano, T.; Petasis, N.A.; Fokin, V.V.; Serhan, C.N. Lipoxin A4 stable analogs are potent mimetics that stimulate human monocytes and THP-1 cells via a G-protein-linked lipoxin A4 receptor. J. Biol. Chem. 1997, 272, 6972-6978. [CrossRef] [PubMed]

75. Carmo, A.A.; Costa, B.R.; Vago, J.P.; de Oliveira, L.C.; Tavares, L.P.; Nogueira, C.R.; Ribeiro, A.L.; Garcia, C.C.; Barbosa, A.S.; Brasil, B.S.; et al. Plasmin induces in vivo monocyte recruitment through protease-activated receptor-1-, MEK/ERK-, and CCR2-mediated signaling. J. Immunol. 2014, 193, 3654-3663. [CrossRef] [PubMed]

76. Kurihara, T.; Warr, G.; Loy, J.; Bravo, R. Defects in macrophage recruitment and host defense in mice lacking the CCR2 chemokine receptor. J. Exp. Med. 1997, 186, 1757-1762. [CrossRef]

77. Cushing, S.D.; Berliner, J.A.; Valente, A.J.; Territo, M.C.; Navab, M.; Parhami, F.; Gerrity, R.; Schwartz, C.J.; Fogelman, A.M. Minimally modified low density lipoprotein induces monocyte chemotactic protein 1 in human endothelial cells and smooth muscle cells. Proc. Natl. Acad. Sci. USA 1990, 87, 5134-5138. [CrossRef]

78. Standiford, T.J.; Kunkel, S.L.; Phan, S.H.; Rollins, B.J.; Strieter, R.M. Alveolar macrophage-derived cytokines induce monocyte chemoattractant protein-1 expression from human pulmonary type II-like epithelial cells. J. Biol. Chem. 1991, 266, 9912-9918.

79. Brown, Z.; Strieter, R.M.; Neild, G.H.; Thompson, R.C.; Kunkel, S.L.; Westwick, J. IL-1 receptor antagonist inhibits monocyte chemotactic peptide 1 generation by human mesangial cells. Kidney Int. 1992, 42, 95-101. [CrossRef]

80. Barna, B.P.; Pettay, J.; Barnett, G.H.; Zhou, P.; Iwasaki, K.; Estes, M.L. Regulation of monocyte chemoattractant protein-1 expression in adult human non-neoplastic astrocytes is sensitive to tumor necrosis factor (TNF) or antibody to the 55-kDa TNF receptor. J. Neuroimmunol. 1994, 50, 101-107. [CrossRef]

81. Park, J.H.; Kim, Y.G.; Shaw, M.; Kanneganti, T.D.; Fujimoto, Y.; Fukase, K.; Inohara, N.; Núñez, G. Nod1/RICK and TLR signaling regulate chemokine and antimicrobial innate immune responses in mesothelial cells. J. Immunol. 2007, 179, 514-521. [CrossRef] [PubMed]

82. Daly, C.; Rollins, B.J. Monocyte chemoattractant protein-1 (CCL2) in inflammatory disease and adaptive immunity: Therapeutic opportunities and controversies. Microcirculation 2003, 10, 247-257. [CrossRef] [PubMed]

83. França, C.N.; Izar, M.C.O.; Hortêncio, M.N.S.; do Amaral, J.B.; Ferreira, C.E.S.; Tuleta, I.D.; Fonseca, F.A.H. Monocyte subtypes and the CCR2 chemokine receptor in cardiovascular disease. Clin. Sci. (Lond.) 2017, 131, 1215-1224. [CrossRef]

84. Cailhier, J.F.; Partolina, M.; Vuthoori, S.; Wu, S.; Ko, K.; Watson, S.; Savill, J.; Hughes, J.; Lang, R.A. Conditional macrophage ablation demonstrates that resident macrophages initiate acute peritoneal inflammation. J. Immunol. 2005, 174, 2336-2342. [CrossRef]

85. Motoyoshi, S.; Yamamoto, Y.; Munesue, S.; Igawa, H.; Harashima, A.; Saito, H.; Han, D.; Watanabe, T.; Sato, H.; Yamamoto, H. cAMP ameliorates inflammation by modulation of macrophage receptor for advanced glycation end-products. Biochem. J. 2014, 463, 75-82. [CrossRef]

86. Mantovani, A.; Sica, A.; Sozzani, S.; Allavena, P.; Vecchi, A.; Locati, M. The chemokine system in diverse forms of macrophage activation and polarization. Trends Immunol. 2004, 25, 677-686. [CrossRef]

87. Martinez, F.O.; Gordon, S. The M1 and M2 paradigm of macrophage activation: Time for reassessment. F1000Prime Rep. 2014, 6, 13. [CrossRef] [PubMed]

88. Murray, P.J. Macrophage Polarization. Annu. Rev. Physiol. 2017, 79, 541-566. [CrossRef] [PubMed]

89. Watanabe, S.; Alexander, M.; Misharin, A.V.; Budinger, G.R.S. The role of macrophages in the resolution of inflammation. J. Clin. Investig. 2019, 130. [CrossRef]

90. Chakravortty, D.; Hensel, M. Inducible nitric oxide synthase and control of intracellular bacterial pathogens. Microbes Infect. 2003, 5, 621-627. [CrossRef]

91. Tavares, L.P.; Garcia, C.C.; Vago, J.P.; Queiroz-Junior, C.M.; Galvão, I.; David, B.A.; Rachid, M.A.; Silva, P.M.; Russo, R.C.; Teixeira, M.M.; et al. Inhibition of Phosphodiesterase-4 during Pneumococcal Pneumonia 
Reduces Inflammation and Lung Injury in Mice. Am. J. Respir. Cell Mol. Biol. 2016, 55, 24-34. [CrossRef] [PubMed]

92. Murray, P.J.; Allen, J.E.; Biswas, S.K.; Fisher, E.A.; Gilroy, D.W.; Goerdt, S.; Gordon, S.; Hamilton, J.A.; Ivashkiv, L.B.; Lawrence, T.; et al. Macrophage activation and polarization: Nomenclature and experimental guidelines. Immunity 2014, 41, 14-20. [CrossRef] [PubMed]

93. Koscsó, B.; Csóka, B.; Kókai, E.; Németh, Z.H.; Pacher, P.; Virág, L.; Leibovich, S.J.; Haskó, G. Adenosine augments IL-10-induced STAT3 signaling in M2c macrophages. J. Leukoc. Biol. 2013, 94, 1309-1315. [CrossRef] [PubMed]

94. Özzes, A.R.; Pulliam, N.; Ertosun, M.G.; Yılmaz, Ö.; Tang, J.; Çopuroğlu, E.; Matei, D.; Özeş, O.N.; Nephew, K.P. Protein kinase A-mediated phosphorylation regulates STAT3 activation and oncogenic EZH2 activity. Oncogene 2018, 37, 3589-3600. [CrossRef] [PubMed]

95. Li, Z.; Feng, P.P.; Zhao, Z.B.; Zhu, W.; Gong, J.P.; Du, H.M. Liraglutide protects against inflammatory stress in non-alcoholic fatty liver by modulating Kupffer cells M2 polarization via cAMP-PKA-STAT3 signaling pathway. Biochem. Biophys. Res. Commun 2019, 510, 20-26. [CrossRef]

96. MacKenzie, K.F.; Clark, K.; Naqvi, S.; McGuire, V.A.; Nöehren, G.; Kristariyanto, Y.; van den Bosch, M.; Mudaliar, M.; McCarthy, P.C.; Pattison, M.J.; et al. PGE(2) induces macrophage IL-10 production and a regulatory-like phenotype via a protein kinase A-SIK-CRTC3 pathway. J. Immunol. 2013, 190, 565-577. [CrossRef]

97. Wein, M.N.; Foretz, M.; Fisher, D.E.; Xavier, R.J.; Kronenberg, H.M. Salt-Inducible Kinases: Physiology, Regulation by cAMP, and Therapeutic Potential. Trends Endocrinol. Metab. 2018, 29, 723-735. [CrossRef]

98. Ozanne, J.; Prescott, A.R.; Clark, K. The clinically approved drugs dasatinib and bosutinib induce anti-inflammatory macrophages by inhibiting the salt-inducible kinases. Biochem J. 2015, 465, 271-279. [CrossRef]

99. Clark, K.; MacKenzie, K.F.; Petkevicius, K.; Kristariyanto, Y.; Zhang, J.; Choi, H.G.; Peggie, M.; Plater, L.; Pedrioli, P.G.; McIver, E.; et al. Phosphorylation of CRTC3 by the salt-inducible kinases controls the interconversion of classically activated and regulatory macrophages. Proc. Natl. Acad. Sci. USA 2012, 109, 16986-16991. [CrossRef]

100. Gilroy, D.W.; Lawrence, T.; Perretti, M.; Rossi, A.G. Inflammatory resolution: New opportunities for drug discovery. Nat. Rev. Drug Discov. 2004, 3, 401-416. [CrossRef]

101. Gordon, S.; Martinez, F.O. Alternative activation of macrophages: Mechanism and functions. Immunity 2010, 32, 593-604. [CrossRef]

102. Greenlee-Wacker, M.C. Clearance of apoptotic neutrophils and resolution of inflammation. Immunol. Rev. 2016, 273, 357-370. [CrossRef]

103. Patel, H.B.; Montero-Melendez, T.; Greco, K.V.; Perretti, M. Melanocortin receptors as novel effectors of macrophage responses in inflammation. Front. Immunol. 2011, 2, 41. [CrossRef] [PubMed]

104. Frasch, S.C.; Bratton, D.L. Emerging roles for lysophosphatidylserine in resolution of inflammation. Prog. Lipid Res. 2012, 51, 199-207. [CrossRef] [PubMed]

105. Frasch, S.C.; Fernandez-Boyanapalli, R.F.; Berry, K.Z.; Leslie, C.C.; Bonventre, J.V.; Murphy, R.C.; Henson, P.M.; Bratton, D.L. Signaling via macrophage G2A enhances efferocytosis of dying neutrophils by augmentation of Rac activity. J. Biol. Chem. 2011, 286, 12108-12122. [CrossRef]

106. Brock, T.G.; McNish, R.W.; Mancuso, P.; Coffey, M.J.; Peters-Golden, M. Prolonged lipopolysaccharide inhibits leukotriene synthesis in peritoneal macrophages: Mediation by nitric oxide and prostaglandins. Prostaglandins Other Lipid Mediat. 2003, 71, 131-145. [CrossRef]

107. Maderna, P.; Yona, S.; Perretti, M.; Godson, C. Modulation of phagocytosis of apoptotic neutrophils by supernatant from dexamethasone-treated macrophages and annexin-derived peptide $\mathrm{Ac}(2-26)$. J. Immunol. 2005, 174, 3727-3733. [CrossRef]

108. Podrez, E.A.; Poliakov, E.; Shen, Z.; Zhang, R.; Deng, Y.; Sun, M.; Finton, P.J.; Shan, L.; Gugiu, B.; Fox, P.L.; et al. Identification of a novel family of oxidized phospholipids that serve as ligands for the macrophage scavenger receptor CD36. J. Biol. Chem. 2002, 277, 38503-38516. [CrossRef] [PubMed]

109. Rossi, A.G.; McCutcheon, J.C.; Roy, N.; Chilvers, E.R.; Haslett, C.; Dransfield, I. Regulation of macrophage phagocytosis of apoptotic cells by cAMP. J. Immunol. 1998, 160, 3562-3568. 
110. Aronoff, D.M.; Carstens, J.K.; Chen, G.H.; Toews, G.B.; Peters-Golden, M. Short communication: Differences between macrophages and dendritic cells in the cyclic AMP-dependent regulation of lipopolysaccharideinduced cytokine and chemokine synthesis. J. Interferon Cytokine Res. 2006, 26, 827-833. [CrossRef]

111. Kumaran Satyanarayanan, S.; El Kebir, D.; Soboh, S.; Butenko, S.; Sekheri, M.; Saadi, J.; Peled, N.; Assi, S.; Othman, A.; Schif-Zuck, S.; et al. IFN- $\beta$ is a macrophage-derived effector cytokine facilitating the resolution of bacterial inflammation. Nat. Commun. 2019, 10, 3471. [CrossRef] [PubMed]

(C) 2020 by the authors. Licensee MDPI, Basel, Switzerland. This article is an open access article distributed under the terms and conditions of the Creative Commons Attribution (CC BY) license (http://creativecommons.org/licenses/by/4.0/). 